\title{
Advances in Homogeneous Catalysis Using Secondary Phosphine Oxides (SPOs): Pre-ligands for Metal Complexes
}

\author{
Thierry Achard*
}

\begin{abstract}
The secondary phosphine oxides are known to exist in equilibrium between the pentavalent phosphine oxides (SPO) and the trivalent phosphinous acids (PA). This equilibrium can be displaced in favour of the trivalent tautomeric form upon coordination to late transition metals. This tutorial review provides the state of the art of the use of secondary phosphine oxides as pre-ligands in transition metal-catalysed reactions. Using a combination of SPOs and several metals such as $\mathrm{Pd}, \mathrm{Pt}, \mathrm{Ru}, \mathrm{Rh}$ and $\mathrm{Au}$, a series of effective and original transformations have been obtained and will be discussed here.
\end{abstract}

Keywords: Metal-catalysed reactions · Phosphinito complexes · Phosphinous acids (PA) · Secondary phosphine oxides (SPO)

Phosphorus is one of the most important atoms for life as it is involved in numerous biological processes. ${ }^{[1]}$ Humans mainly use phosphorus in its phosphate form as fertilizer to feed and grow plants. Furthermore, our cells require pentavalent phosphorus to build membranes (phospholipids), transport energy (ATP) and replicate (DNA, RNA). Chemists prefer the use of the trivalent phosphorus and trialkyl/aryl phosphines in particular. These molecules are involved in several standard organic transformations such as the Mitsunobu-, Vilsmeier-, and Wittig reactions and many more. But the most exploited facet of phosphine derivatives is their ability to bind transition metals. ${ }^{[2]}$ In organometallic chemistry and homogenous catalysis they represent the ligand of choice due to their ability to stabilize an exceptionally wide variety of metal centres. ${ }^{[3]}$ However, one major issue still remains for most trivalent phosphorus compounds: their sensitivity to oxidation. So, their preparation often requires an inert gas atmosphere, not exactly an advantage for routine use and scale-up. Protection through $\mathrm{BH}_{3}$ groups can be achieved, but the in situ release of the free phosphine needs the presence of an amine that must be done prior to any coordination to transition metals. ${ }^{[4]}$ Unfortunately, the $\mathrm{P}-\mathrm{BH}_{3}$ adduct is often unstable towards a series of acids and Lewis bases.

${ }^{*}$ Correspondence: Dr. T. Achard

University of Strasbourg, IPCMS: UMR 7504 CNRS Département des Matériaux Organiques (DMO)

23 rue du Loess BP 43, Strasbourg 67034

E-mail: thierry.achard@ipcms.unistra.fr
For trialkyl phosphine oxide (TPO) the pentavalent phosphorus loses its coordinating ability in favour of the oxygen atom. However, secondary phosphine oxides (SPOs) are in equilibrium with pentavalent phosphine oxide and trivalent phosphinous acids. ${ }^{[5]}$ It is well established that in presence of a transition metal, the equilibrium is displaced in favour of the phosphinous acid (PA) through coordination of the phosphorus atom (Scheme 1). ${ }^{[6]}$

The secondary phosphine oxides present a remarkable dichotomy in their coordination mode (monodentate versus bidentate). In addition, the $\mathrm{P}=\mathrm{O}$ group displays an interesting ambident character that can chelate either late-transition metals (M1) through the 'soft' phosphorus atom or early transition metals (M2) through the ' $h a r d$ ' oxygen atom (Scheme 2). ${ }^{6 a, 7]}$

Neutral ligands generate complexes of type (a) and (c): the P-coordination mode (a) was found to accommodate $\mathrm{Fe}, \mathrm{Ir}, \mathrm{Pd}$, $\mathrm{Pt}, \mathrm{Rh}$ and $\mathrm{Ru}$ transition metals, whereas mode (c) was only described with $\mathrm{Cr}$, Mo, W, Re, Ti and observed for Rh. ${ }^{[6 a, 7,8]}$ In the

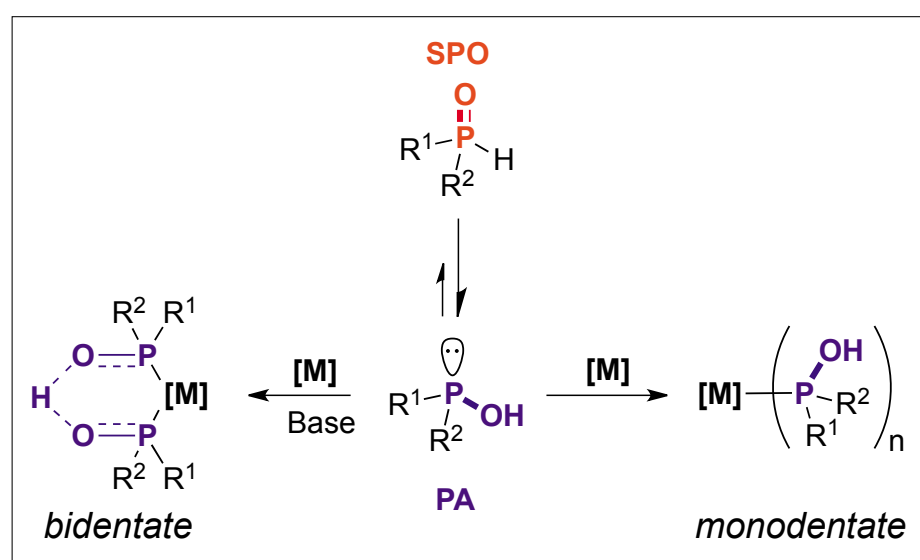

presence of a base the weak PA acids ${ }^{[9]}$ can be easily deprotonated into anionic phosphinito ligands that generate P-coordinated type (b) complexes or O-metalated species of type (d) (Scheme 2). Such anionic ligands combine with Mo, W, Mn, Re, Fe, $\mathrm{Pt}$ and $\mathrm{Au}$ to form preferentially type (b) complexes. In contrast, with $\mathrm{Fe}, \mathrm{Rh}, \mathrm{Ir}$ and $\mathrm{Ag}$, the O-coordination (type d) is favoured. Representative X-ray structures of type (a) and (c) complexes are highlighted in Fig. 1.[10]

Phosphinito ligands can adopt the bridging mode (e) on several transition metals such as $\mathrm{Cr}, \mathrm{Mn}, \mathrm{Re}, \mathrm{Fe}, \mathrm{Co}, \mathrm{Ni}$, Ir, $\mathrm{Pd}, \mathrm{Pt}$ and $\mathrm{Au} .{ }^{[6 a, 7]}$ In this case, the system often displays a six-membered ring unit $\left[\mathrm{M}_{2}\left(\mu-\mathrm{SPO}_{2}\right)\right]$ involving two metals bridged by two SPO ligands. Outstandingly, a few examples with Mo, W, Rh and Ir show a rare dihapto coordination mode of type (f). This monomeric unit was often postulated in equilibrium with the dinuclear complex (e). ${ }^{[7 a]}$ Representative X-ray structures of type (e) complexes are highlighted in Fig. 2.[10]

Scheme 1. SPO-PA tautomeric equilibrium and chelate formation. 

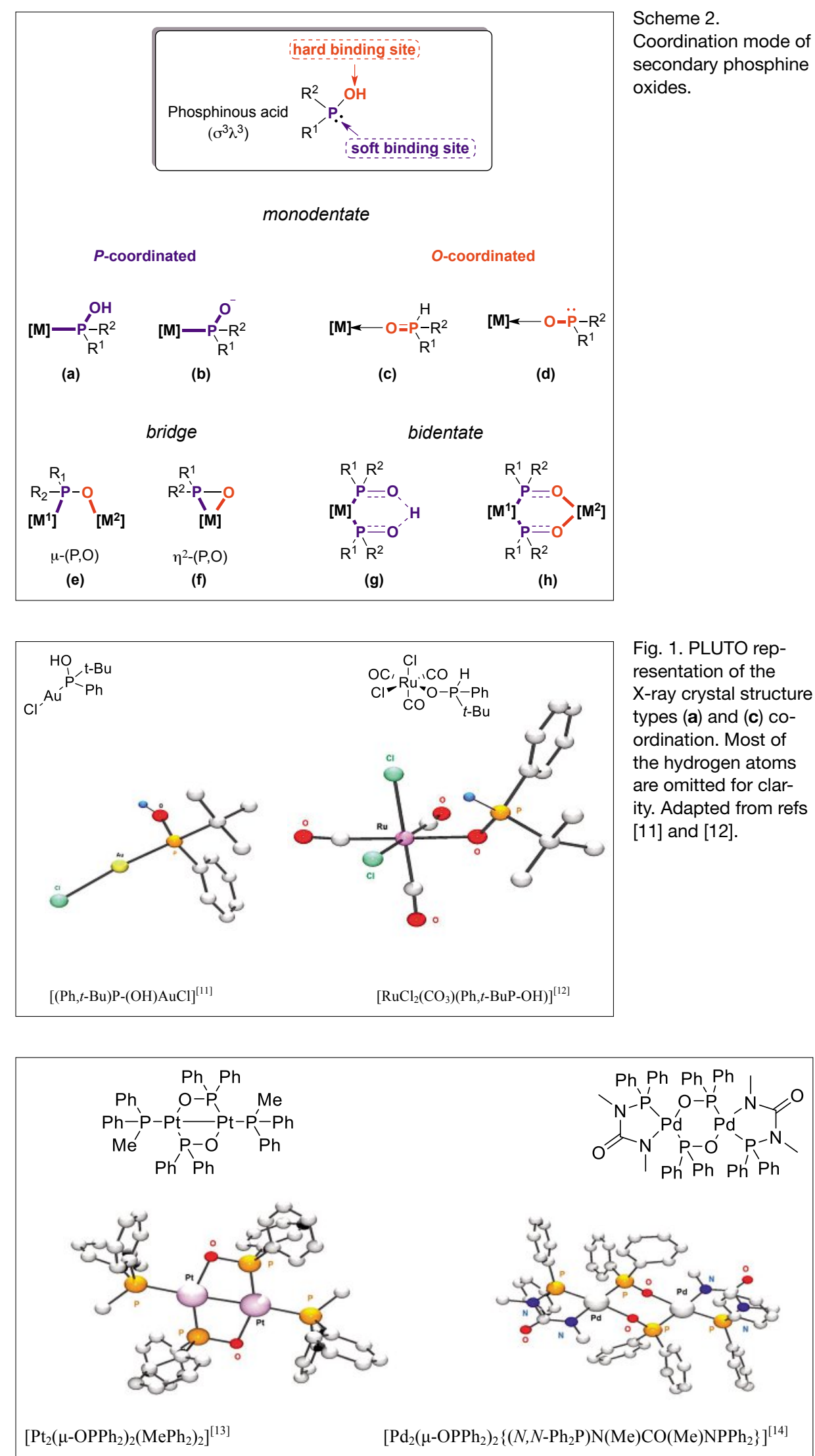

Fig. 2. PLUTO representation of the X-ray crystal structure type (e) coordination. Most of the hydrogen atoms are omitted for clarity. Adapted from refs [13] and [14].

Interestingly, two SPOs ligands attached on the same metal centre can form an intramolecular hydrogen bond into the backbone and so 'mimic' a bidentate ligand to give a monoanionic diphosphorus
Fig. 1. PLUTO representation of the $\mathrm{X}$-ray crystal structure types (a) and (c) coordination. Most of the hydrogen atoms are omitted for clarity. Adapted from refs

[11] and [12].

Scheme 2.

Coordination mode of oxides. results from a combination of a neutral ligand of type (a) with an anionic ligand of type (b). The formation of a strong hydrogen bond is definitely the driving force for this favoured coordination mode. However, steric hindrance at the phosphorus atom can prevent the formation of such a complex by preferring a trans configuration between the two SPO units. ${ }^{[15]}$ This bidentate behaviour has been observed for numerous transition metals such as $\mathrm{Cr}$, Mo, W, Ru, Rh, Ir, Pd and Pt.[6a,7] Representative X-ray structures of type (g) complexes are highlighted in Fig. 3.[10]

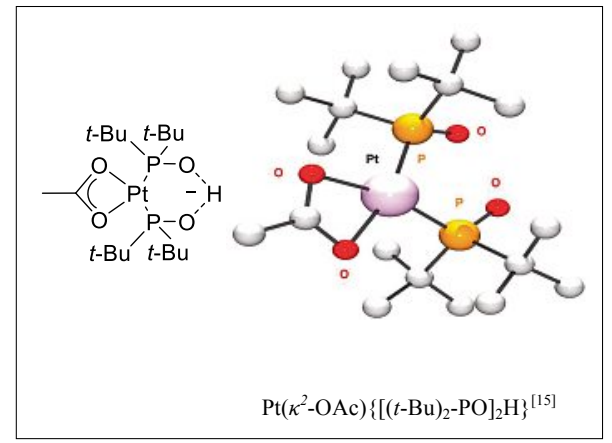

Fig. 3. PLUTO representation of the X-ray crystal structure type (g) coordination. Most of the hydrogen atoms are omitted for clarity. Adapted from ref. [15].

Captivatingly, the acidic bridging hydrogen can be replaced by a wide variety of metals (Al, $\mathrm{Co}, \mathrm{Cu}, \mathrm{Ir}, \mathrm{Mn}, \mathrm{Na}, \mathrm{Ni}, \mathrm{Rh}$, Th, T1, U, V and Zn) providing bimetallic species of type (h). Other coordination compounds have been reported in the literature in which the proton is replaced by non-metal atoms such as B, Si and P. Representative X-ray structures of type (h) complexes are highlighted in Fig. 4.[10]

Electronic properties of SPO ligands have been investigated by Martin et al. on various metal carbonyl SPO-complexes by the measurement and/or calculation of the IR frequencies of CO. ${ }^{[18]}$ It appears that generally the phosphinous acid form (a) is less donating than the corresponding trisubstituted phosphine ligands. However, abstraction of the hydrogen makes the generated phosphinito (b and e) an extremely strong donating ligand (Tolman's electronic parameter (TEP) ranging from 2006 to $2028 \mathrm{~cm}^{-1}$ ). According to both their TEPs and $\tilde{v}_{\mathrm{CO}}$ frequencies, bidentate anionic ligands of type (g) display the strongest net-donation (close to phosphonium ylides) outclassing the N-heterocyclic carbenes. Finally, the net-donation decreases in the presence of an alkali ion $\mathbf{M}^{2}$ (type $\mathbf{e}$ and $\mathbf{h}$ ) and the magnitude of this effect directly correlates to the hardness of the counter ion. Electronic modulation can be easily achieved by varying the nature of the group bound to the phosphorus atom. Interestingly electron-poor SPOs (depicted in Scheme 1) shift the equilibrium in favour of phosphinous acid form making them ideal candidates to form metal complexes. ${ }^{[10]}$ 


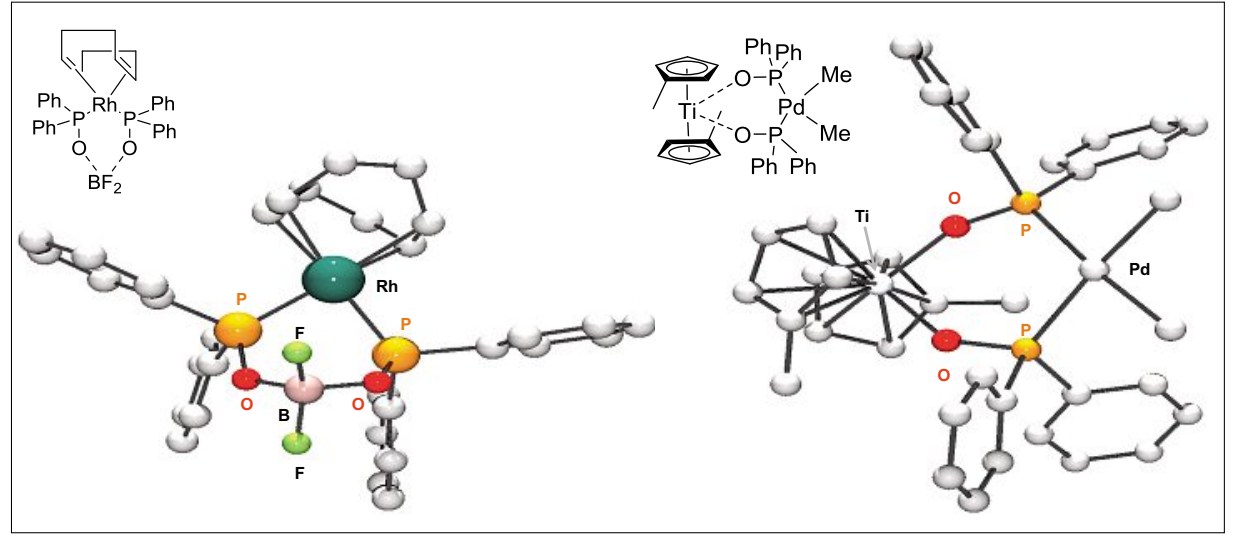

Fig. 4. PLUTO representation of the X-ray crystal structure type (h) coordination. Most of the hydrogen atoms are omitted for clarity. Adapted from refs [16] and [17].

Steric properties have to be taken into account as they play a crucial role on both the formation of metal complexes and their coordination mode. Indeed, in square planar complexes such as $\mathrm{PtCl}_{2}$ (cod) and ( $\left[\left\{\mathrm{Rh}(\mathrm{CO})_{2} \mathrm{Cl}\right\}_{2}\right]$, the bulky and electronrich SPOs such as $(t-\mathrm{Bu})_{2} \mathrm{P}-\mathrm{OH}$ react to form exclusively trans-platinum complexes $\left[\mathrm{ML}_{2}\left(t-\mathrm{Bu}_{2} \mathrm{POH}\right)_{2}\right]$. $^{[15,17]}$ Moreover, the same ligands do not react with bulkier $\left[\mathrm{Rh}(\mathrm{cod})_{2}\right]\left[\mathrm{BF}_{4}\right]$ precursors mainly due to steric hindrance of the $t$-Bu groups. ${ }^{[17]}$ Furthermore, because of that it is difficult to locate the two phosphorus groups in the required cis geometry to form the 'pseudo-bidentate' complex and only rare examples have been described in the literature. ${ }^{[15,18,19]}$

Finally, it is important to note that the electronic donation of such a ligand can be dramatically modified during the course of the reaction. Indeed, phosphinous acids are able to reversibly form strong electron-donating phosphinito species upon deprotonation. This facet is quite unique and could be the source of their exceptional behaviour as catalysts.

Since 1986 and the first application reported by van Leeuwen et al. on the (SPO) Pt-catalysed hydroformylation of olefins, ${ }^{[20]}$ the use of SPO-catalysts has gained great interest. The main reasons for their use as pre-ligands could be summarised as follows: i) more stable to oxidation than the parent phosphine; ${ }^{[21]}$ ii) fairly simple syntheses and ease to modulate both steric and electronic factors; $[15,21,22]$ iii) strong electron-donating groups $^{[18]}$ between $\pi$-accepting phosphite-like compounds and beyond N-heterocyclic carbenes. ${ }^{[21,23]}$ All these properties are indeed suitable for both organometallic chemistry and homogenous catalysis. In this review, recent advances in this area will be discussed. We will confine mostly our discussion to the past five years on catalytic reactions; cross-coupling reactions will be briefly mentioned as reviews were recently published on this topic. [24]
Secondary phosphine oxides bind several transition metals giving a rich family of potential catalysts. The following section will discuss their catalytic activities classified by the metal centre involved in these processes.

\section{Palladium-Phosphinous Acid Complexes}

\section{Coupling Reactions}

SPO complexes with a palladium centre have remained the most widely investigated since the report by $\mathrm{Li}$ and co-workers [25] in 2001 on applications in cross-coupling reactions. Complexes such as POPd and POPd1 (Fig. 5) have been successfully applied in a broad range of cross-coupling reactions such as the Heck reaction, [26] Stille coupling, [27] Sonogashira coupling, [28] Hiyama coupling, [29] Kumada coupling, ${ }^{[30]}$ Negishi coupling, ${ }^{[31]}$ SuzukiMiyaura coupling, ${ }^{[32]}$ cross coupling of acyl chlorides with boronic acids ${ }^{[33]}$ or organostannanes, ${ }^{[34]}$ direct $\mathrm{C}(3)$ arylation of indoles, ${ }^{[35]}$ conjugate addition of arylsiloxanes, ${ }^{\left[{ }^{36]}\right.}$ intramolecular $\alpha$-arylations of amides, ${ }^{[37]}$ and oxidative esterification of aldehydes. ${ }^{[38]}$ These catalysts allow crosscoupling reactions to proceed at room temperature even with deactivated aryl chlorides and fluorides.[24a]

However, the development of 'greener' reaction conditions such as replacement of toxic organic solvents by water is still an issue. Hu and co-workers reported an efficient Suzuki cross-coupling reaction of aryl halides in water (Scheme 3$){ }^{\left[{ }^{39]}\right.}$ POPd $(\mathrm{R}=t-\mathrm{Bu})$ catalyst $(0.2 \mathrm{~mol} \%)$ in presence of phenyl boronic acid, appropriate phenyl halides $\mathbf{1}$ and a phase transfer agent $\left(n-\mathrm{Bu}_{4}\right) \mathrm{NBr}$ in refluxing water gave biaryl 2 in good yields. ${ }^{[39}$ a] The authors reported that substrates with electron-donating or -withdrawing substituents were converted to functionalized biphenyls. Using these heterogeneous conditions the authors were able to promote the reaction also using heteroaryl bromides 3 and 5. ${ }^{[39 b, c]}$ This system allows an easy separation of the catalyst generating the desired compound in high purity.

The combination of imidazole-based secondary phosphine oxide ${ }^{[40]}$ and palladium acetate (under mild conditions: $60{ }^{\circ} \mathrm{C}$ ), promoted a highly regioselective Heck coupling reaction as described by Shaikh and Hong. ${ }^{40]}$ They demonstrated that the coupling of aryl halides and olefins in the presence of $\mathrm{K}_{2} \mathrm{CO}_{3}$ in DMF solvent was promoted using $1.5 \mathrm{~mol} \%$ of complex 7 resulting in the formation of exclusive trans-stilbene derivatives in good yields (Scheme 4). ${ }^{[41]}$ These reaction conditions could be applied to the synthesis of $\alpha, \beta$ -

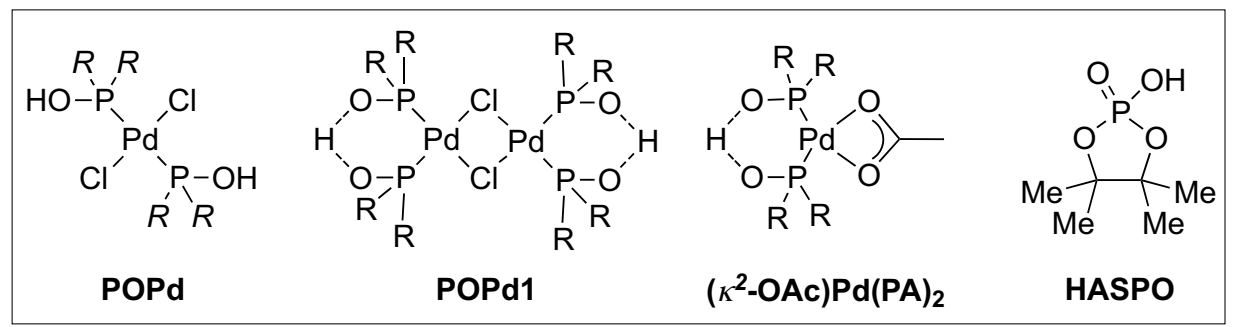

Fig. 5. Selected phosphinous acid-coordinated palladium complexes.

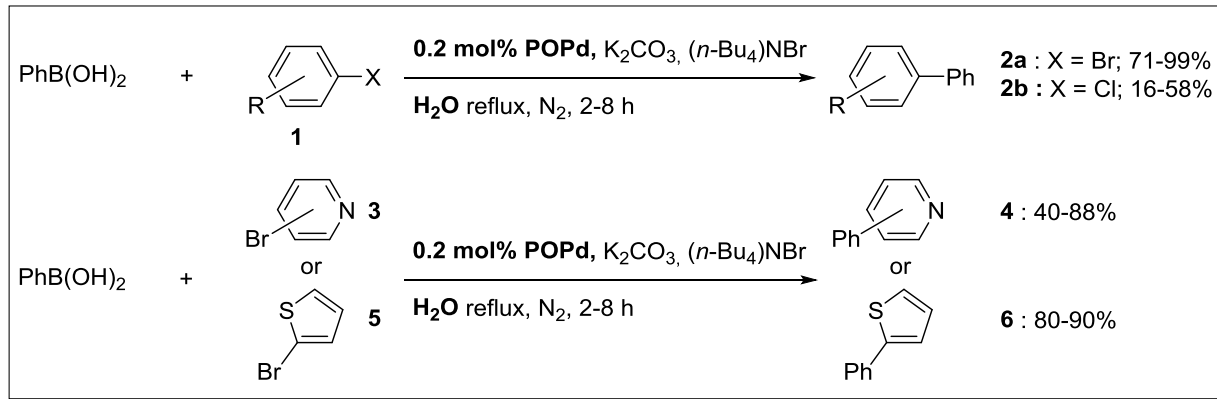

Scheme 3. Suzuki coupling reaction in water catalysed by SPO-Pd. 
unsaturated esters from vinyl ester substrates. Various functional groups such as hydroxyl, carbonyl, nitrile etc. were tolerated using this mild procedure.

The Hong group also reported the preparation of a quinolyl-substituted secondary phosphine oxide hemilabile pre-ligand $\mathbf{8}$. In combination with palladium this modified SPO 8 catalysed $\mathrm{C}-\mathrm{C}$ bond formation in a three-component reaction of olefins $\mathbf{9}$, aryl halides $\mathbf{1 0}$ and carbon monoxide to form polycyclic compounds 11 (Scheme 5). ${ }^{[42]}$

\section{Cycloaddition Reactions}

SPO-Pd complexes displayed very interesting cycloaddition reactions leading to bicyclic compounds. Buono and co-workers recently revealed unprecedented SPOPd 14 (SPO-Pt 18 is described in the next section) catalysed [2+1] cycloadditions of alkynes with norbornadiene derivatives, which afford only the vinylidene cyclopropanes $\mathbf{1 2}$ rather than the expected standard alkynyl products (Scheme 6). This strategy was extended to afford bicyclo[3.2.1] octadienes by a tandem cycloaddition-ring expansion reaction. ${ }^{[43]}$ This time norbornene in presence of propargylic acetate gives a mixture of an unusual ring expanded major product $\mathbf{1 3}$ and cycloadduct $\mathbf{1 2}$ as minor products (Scheme 6). ${ }^{[44]}$

\section{Platinum-Phosphinous Acid Complexes}

In comparison with SPO-palladium complexes, only a few reactions have been described in the literature using a SPOplatinum combination. Since the hydroformylation depicted by Van Leeuwen et $a l .,^{[20]}$ only nitrile hydration and cycloaddition reactions have been reported so far.

\section{Nitrile Hydration}

In 1995, Ghaffar and Parkins reported nitrile hydration using $\mathrm{PtH}\left(\mathrm{PMe}_{2} \mathrm{OH}\right)$ $\left\{\left(\mathrm{PMe}_{2} \mathrm{O}\right)_{2} \mathrm{H}\right\}$ and $\mathrm{PtCl}\left(\mathrm{PMe}_{2} \mathrm{OH}\right)$ $\left\{\left(\mathrm{PMe}_{2} \mathrm{O}\right)_{2} \mathrm{H}\right\} \quad$ (15) under homogenous conditions. ${ }^{[45]}$ The hydrido-platinum(II) complex selectively catalyses the hydration of a wide range of bulky, unsaturated,

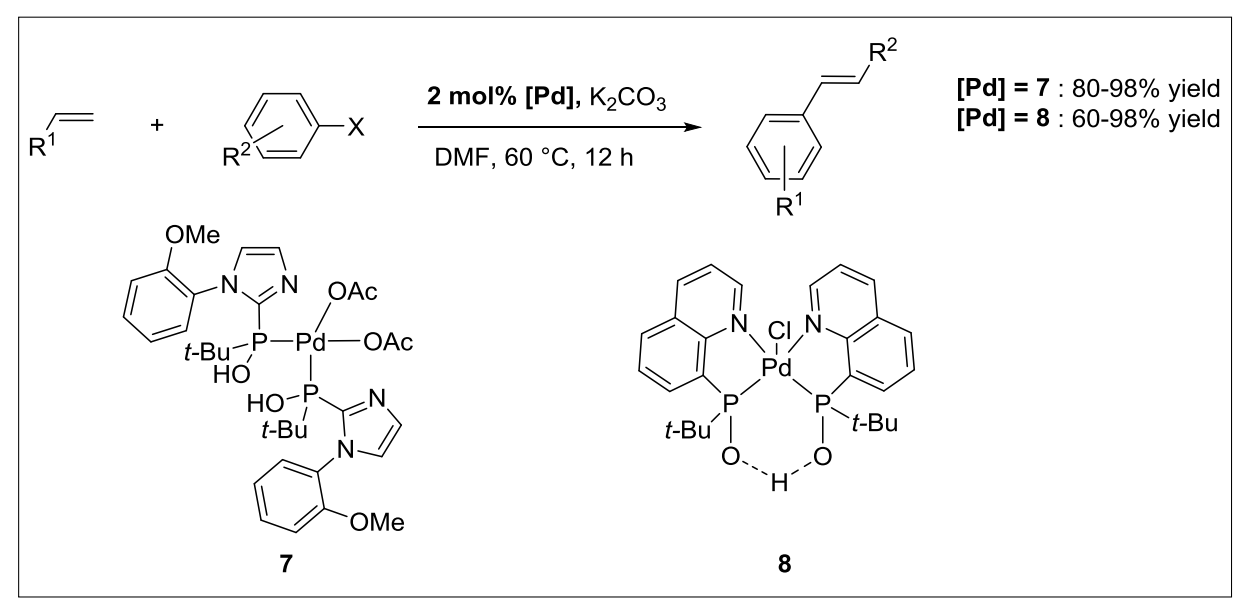

Scheme 4. SPO-Pd catalysed Heck coupling reaction.

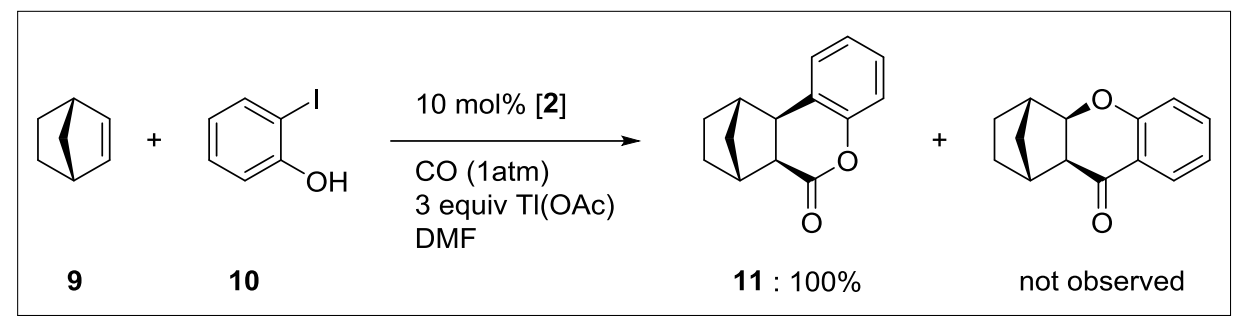

Scheme 5. SPO-Pd catalysed mutli-component reaction (MCR).

base-sensitive functional groups containing nitriles under quite mild $\left(70-100{ }^{\circ} \mathrm{C}\right)$ and neutral reaction conditions in water. ${ }^{[45]}$ Since that time, a number of other studies have been conducted using commonly a water/organic solvent mixture as reaction medium. ${ }^{[46]}$

The catalytic hydration of cyanohydrins 16 remains an important and challenging transformation due to the easy decomposition of cyanohydrins under basic conditions and high temperature, producing undesired HCN. ${ }^{[47]}$ The cyanide released in solution binds irreversibly the metallic centre of the catalyst, annihilating its catalytic activity. ${ }^{[48]}$ Latterly, $\mathrm{PtCl}\left(\mathrm{PMe}_{2} \mathrm{OH}\right)$ $\left\{\left(\mathrm{PMe}_{2} \mathrm{O}\right)_{2} \mathrm{H}\right\}$ was used in a pure aqueous medium to catalyse the hydration of cyanohydrins (Scheme 7). [49] It showed moderate activity compared to classic nitrile substrates, the reaction was slow and only few turnovers could be achieved.[49a] This lack of reactivity was assumed to be due to the partial decomposition of the substrate which generated HCN that definitely poisoned the catalyst. Attempts to modify the substituents on the phosphorus atom to increase the catalytic activity were unfruitful. According to the authors, the formation of the catalyst $\mathrm{PtCl}\left(\mathrm{PMe}_{2} \mathrm{OH}\right)$ $\left\{\left(\mathrm{PMe}_{2} \mathrm{O}\right)_{2} \mathrm{H}\right\}$ is governed by steric effects, generating (when $\mathrm{P}$-alkyl $\neq \mathrm{Me}$ ) the inactive dimer species instead of the expected active monomer complex.[49b]

\section{Cycloaddition Reactions}

The first carbon-carbon bond formation using SPO-Pt complexes was reported using acetate $\mathrm{Pt}\left(\mathrm{K}^{2}\right.$-acetato $)-\{[(\mathrm{R})$ $\left.(\mathrm{Ph}) \mathrm{PO}]_{2} \mathrm{H}\right\}$ as catalyst. These acetatecomplexes 18 promoted benzylidenecyclopropanation of bicyclic alkene through an intermolecular [2+1] cycloaddition (Scheme 6). ${ }^{[19 a]}$ The reaction proceeds under mild reaction conditions $\left(20 \mathrm{~h}\right.$ at $\left.55^{\circ} \mathrm{C}\right)$ and the acetic acid was found crucial to

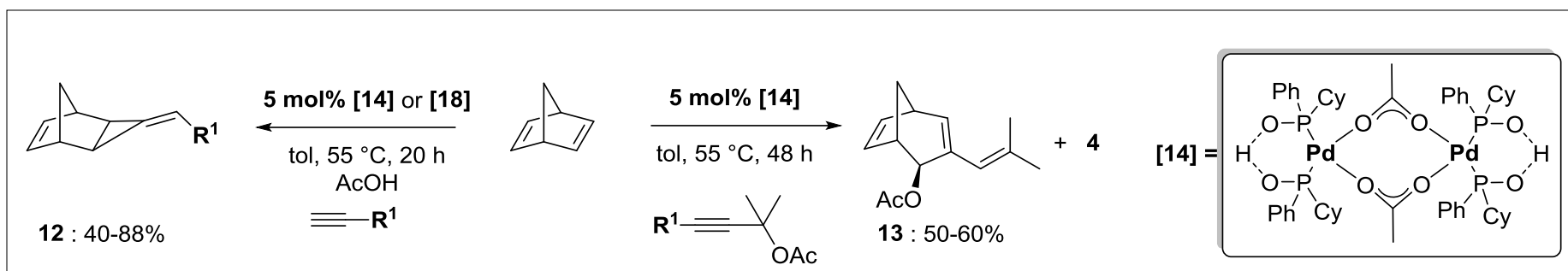

[2+1] cycloaddition

[2+1] cycloaddition/ring expansion 
obtain methylenecyclopropane adducts in good yield (up to 80\%). Interestingly, even hetero olefins such as diaza- and oxyazabicyclic substrates resulted in the formation of the products in excellent yields.

More recently, Achard et al. described an unprecedented platinum-SPO 18 catalysed regio- and diastereoselective tandem $[2+1] /[3+2]$ intermolecular cycloaddition (Scheme 8). ${ }^{[50]}$ This sequence allows the formation of tricyclic compounds 19 in good overall yields by the reaction of norbornadiene with several alkynes. Interestingly, using simple alkynes, such as phenyl acetylene, only provides a methylenecyclopropane (MCP) compound $\mathbf{1 2}$ as already observed for palladium catalysis (Scheme 6). This highlighted the key role of the homopropargylic oxygen atom in this transformation where the MCP compound is the intermediate of this tandem reaction. The authors later expanded this method to the intermolecular cycloaddition of alkylidenecyclopropane and terminal alkynes.[50] Tricyclic architecture compounds 20 were generated bearing various functional groups such as hydroxyl, ether, trimethylsilyl ether, trimethylsilylethyne, sulfonamide, phthalimide and sulfonyl.

\section{Ruthenium-Phosphinous Acid Complexes}

Since the seminal paper of Ackermann et al. on the directed ortho-arylation of benzene catalysed by a ruthenium/SPO combination, ${ }^{[51]}$ other $\mathrm{C}-\mathrm{H}$ functionalizations ${ }^{[23 b, 52]}$ have been described using this base-assisted catalytic system. ${ }^{[53]}$ The use of SPOs in such transformations shows many advantages: i) accelerated reaction, ii) use of a broad range of organic electrophiles (challenging aryl chlorides or tosylates), iii) tolerance towards a lot of functional groups (ester, ketones, cyano, etc.), iv) the robustness of their rutheno-complexes that allows the reaction to proceed in water. ${ }^{[53]}$

\section{Direct C-H Bond Arylations}

Recently, Ackermann et al. showed that sterically hindered SPO 21 combined with ruthenium was even able to promote the first direct arylation of heteroarenes such as 2-pyrimidyl-substituted indoles 22 (Scheme 9).[52c] This base-assisted catalytic system allows the use of cheaper aryl chlorides 23 giving satisfactory yields of arylated products $\mathbf{2 4}$. For aryl bromide substrates, even if SPOs 21 were able to catalyse the reaction, the most efficient catalysis was performed with a bulky carboxylic acid.

Finally, bis-adamanthyl SPO 21 catalyses the direct arylation of phenol such as 2-phenoxypyridine but again carboxylic

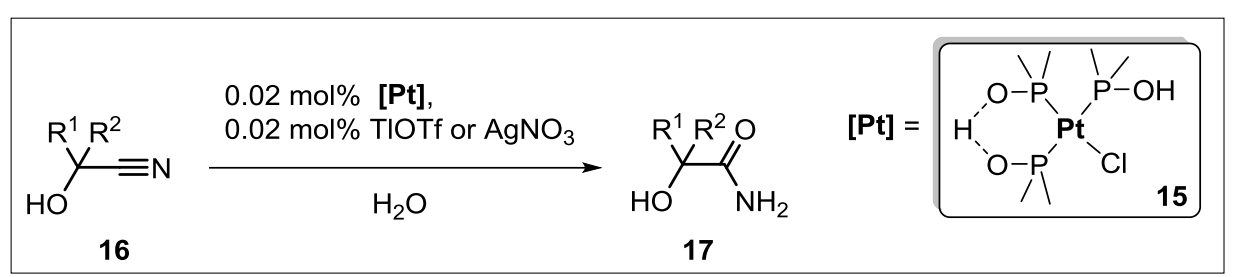

Scheme 7. Hydration of cyanohydrins catalysed by SPO-platinum complexes.

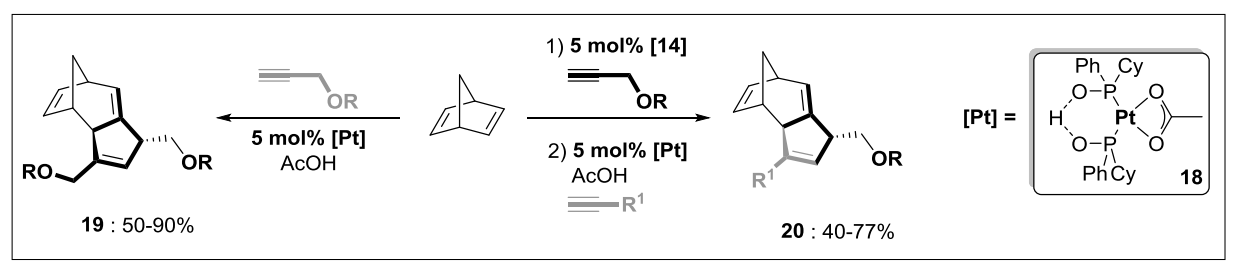

Scheme 8. Pt/SPO-catalysed tandem $[2+1] /[3+2]$ cycloaddition reaction. acid displayed better activity for this reaction. ${ }^{[54]}$

\section{Nitrile Hydration}

As described in the platinum section, hydration of cyanohydrin could be catalysed by transition metal complexes (Pt, $\mathrm{Mo}, \mathrm{Ru})$. Ruthenium catalysts are particularly effective in nitrile hydration reactions and promising results have been described using phosphine ${ }^{[55]}$ and SPO ligands. ${ }^{[48,56]}$ Tyler and co-workers used the ability of SPOs to form hydrogen bonds in the secondary coordination sphere to activate water molecules in order to increase the reaction rate of nitrile hydration. ${ }^{[56]}$ The $\left[\mathrm{Ru}(p \text {-cymene }) \mathrm{Cl}_{2}\right]_{2}$ metal precursor, in the presence of appropriate SPOs, generates the desired $\left[\mathrm{RuCl}_{2}(p \text {-cymene })\left\{\mathrm{PR}_{2}(\mathrm{OH})\right\}\right]_{2}$ species. Good results were obtained with $\mathrm{PMe}_{2}(\mathrm{OH})$ derivatives (TOF up to $32 \mathrm{~h}^{-1}$ at $100^{\circ} \mathrm{C}$ ) which displayed the highest hydrogen bond accepting characters of the SPOs evaluated by the authors. Thereby, the activation of water molecules by the ligand would favour its nucleophilic addition to the metal-coordinated nitrile. The ruthe- nium complex is active in the hydration of various nitriles including several cyanohydrins ( $\alpha$-hydroxynitriles). As observed for other catalysts, this SPO-Ru complex is sensitive to cyanide poisoning and so was not good enough to transform the acetone cyanohydrin to $\sigma$-hydroxyamide. Despite this, $\left[\mathrm{RuCl}_{2}(p \text {-cymene })\left\{\mathrm{PMe}_{2}(\mathrm{OH})\right\}\right]_{2} \mathbf{2 5}$ (Fig. 6) remains the best catalyst, having the highest reaction rate described in the literature for such transformations.

Inspired by these results, Cadierno and co-workers, described the easy preparation and the use of $\left[\mathrm{RuCl}_{2}(p\right.$-cymene) $\left.\left\{\mathrm{PMe}_{2}(\mathrm{OH})\right\}\right]_{2}$ complex $\mathbf{2 6}$ as catalyst in the hydration of nitrile. ${ }^{57]}$ This SPO $\mathrm{Ru}(\mathrm{IV})$ complex displayed a remarkably high catalytic activity $\left(\mathrm{TOF}=100 \mathrm{~h}^{-1}\right)$ in pure water without the assistance of any acidic or basic co-catalyst. The transformation proceeded cleanly under very mild conditions $\left(60^{\circ} \mathrm{C}\right)$ with low catalyst loading (1 mol\%, see Scheme 10a) generating desired amides 29. However, catalyst 26 is able to hydrate demanding cyanohydrin $\mathbf{3 0}$ and can be easily recovered at the end of the reaction (Scheme 10b).

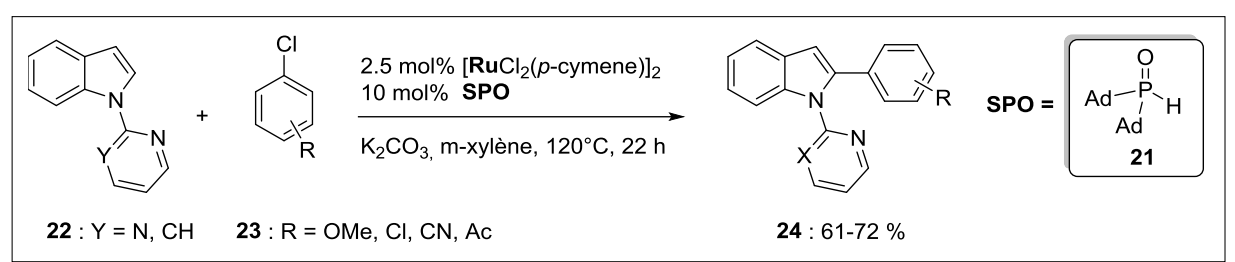

Scheme 9. Direct $\mathrm{CH}$ bond arylation catalysed by SPO-Pt complexes.

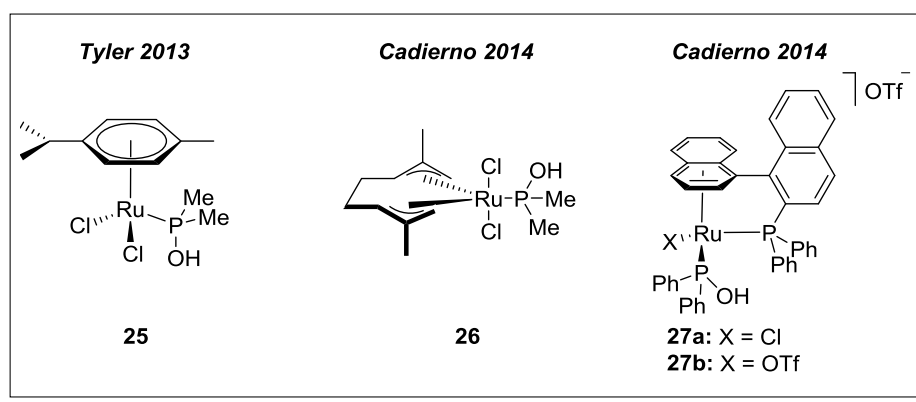

Fig. 6. Selected phosphinous acid-coordinated ruthenium complexes. 
The authors extended their studies using a cationic ruthenium complex derived from a Binap core. The triflate complex $\left[\operatorname{RuOTf}\left\{\left(\eta^{6}: \kappa^{1}(P)-\mathrm{PPh}_{2}-\mathrm{Binaph}_{\mathrm{n} y \mathrm{l}}\right\}\right.\right.$ $\left.\left\{\mathrm{PPh}_{2}(\mathrm{OH})\right\}\right][\mathrm{OTf}](\mathbf{2 7 b})$ is an efficient catalyst for the hydration of nitrile in pure water. ${ }^{[58]}$ However, this metal complex was found to be much more sensitive to steric hindrance as $24 \mathrm{~h}$ were required to achieve full conversion of bulkier nitriles. Finally, cationic SPO-Ru $\mathbf{2 7 b}$ remains less active compared to neutral cymene $\mathbf{2 5}$ and bisallyl-ruthenium 26 complexes. Noteworthy, this ruthenium complex $27 \mathbf{b}$ catalyses the rearrangement of aldoximines $\mathbf{3 2}$ to amides via a dehydration/hydration sequence involving the nitrile intermediate. Good results were obtained (conversions up to $99 \%$ and yields up to $87 \%$ ) using the same reaction conditions $(5 \mathrm{~mol} \%$ of $[\mathrm{Ru}]$ in water at $100{ }^{\circ} \mathrm{C}$, Scheme 11).

\section{Hydrogenation Using Ru-Nano- particles}

In a relevant observation, Wang and Buhro reported that the presence of dioctylphosphine oxide (impurities in $\mathrm{Cy}_{3} \mathrm{P}$ ) strongly altered the morphology of CdSe nanocrystals during their formation. [59] Inspired by this work, Van Leeuwen and co-workers investigated SPOs for the stabilisation of ruthenium nanoparticles (RuNPs). ${ }^{60]}$ SPOs possessing different electronic and steric properties were combined with the nanoparticles in a SPO/Ru: 0.2/1 ratio. Diphenylphosphine oxide 33 provided the most narrow size distribution of particles minimizing their agglomeration (average diameter $1.6 \mathrm{~nm}$; $\left[\mathrm{Ru}_{147}\left(\mathrm{Ph}_{2} \mathrm{P}(\mathrm{O})\right.\right.$ $\left.\mathrm{H})_{13}\right]$ ). Despite the ability of SPOs to form very stable molecular complexes, ${ }^{[17,23 a]}$ they were found to be very efficient to stabilize Ru-L NPs. The surface of the particles was carefully analysed showing that all the SPO pre-ligands were coordinated in a network of hydrogen bonds.

The authors evaluated these SPORuNPs in the hydrogenation of aromatic compounds 34 (Scheme 12). These SPORuNPs are highly active using only $<0.01$ $\mathrm{mol} \%$ of nanoparticles in neat conditions. The catalyst loading could be reduced to 1:16000 whilst maintaining the high yields (TOF $2700 \mathrm{~mol} \mathrm{~h}^{-1}$; TON 16200) of hydrogenated compounds even for deactivated trifluorotoluene substrates.

\section{Cycloisomerisation of Arenynes}

According to the literature it is not trivial to synthesise Ru/SPOs complexes and only a few arene-containing complexes have been well characterised. ${ }^{[55,57,61]}$ Very recently, Clavier and co-workers described the preparation of ruthenium carbonyl complexes bound either to one SPO or two PA ligands. ${ }^{[12]}$ They showed interesting coordination behaviour depending on the re-

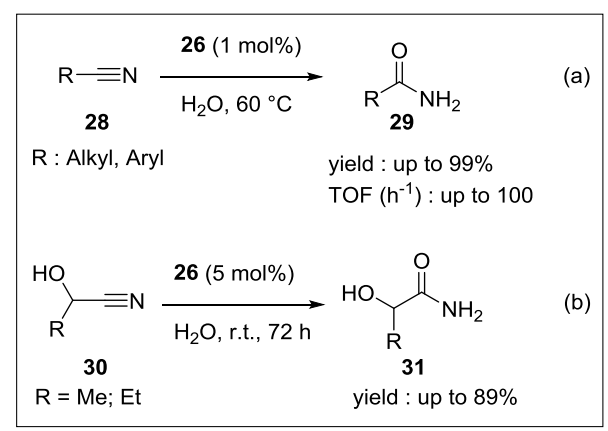

Scheme 10. Catalytic hydration of nitriles to amide in water catalysed by SPOs-Ru complexes.

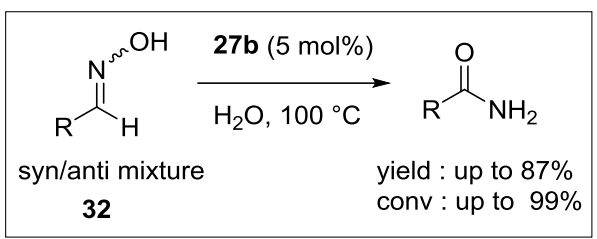

Scheme 11. Catalytic rearrangement of aldoximines to amides catalysed by SPOs-Ru complexes.
In the presence of SPO-Ru complexes and silver triflate salts, electron-rich arenynes $37(\mathrm{R}=\mathrm{OMe})$ reacted to give bicyclic compounds 38. Ru complexes with electron-rich SPOs such as $\mathrm{Cy}_{2} \mathrm{POH}$ were found to be the most active catalysts giving full conversion after $8 \mathrm{~h}$ with only $2 \mathrm{~mol} \%$ of ruthenium (Scheme 14). Less active arenynes $37(\mathrm{R}=\mathrm{H})$ need thermal activation up to $80{ }^{\circ} \mathrm{C}$ and provide mostly the isomer 39a. The author shows that there is no and the observed selectivity; the selectivity methoxy group. ${ }^{[12]}$ However, in this case combination of the less donating and more sterically demanding $t$ - $\mathrm{BuPhPOH}$ ligand and ruthenium efficiently catalyses this reaction contrasting with the previous substrate. This suggests a strong relationship between ligand and substrate structures and so different rate-determining steps might be considered for the two different substrates. According to the author, electron-poor complexes seem to activate efrelation between the shape of the catalyst seems only related to the steric effect of the

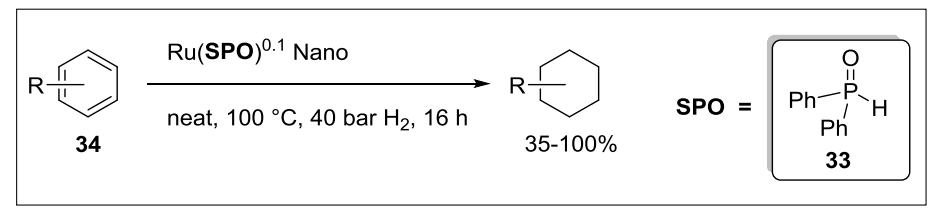

Scheme 12. Hydrogenation of benzene derivatives. action conditions used for the synthesis of SPO-Ru complexes. Using one equivalent of SPO under mild conditions generated only the O-coordinated compounds 35ad, in contrast P-coordinated compounds 36a-g were obtained using harsher reaction conditions (two equiv. of SPOs at 110 ${ }^{\circ} \mathrm{C}$, see Scheme 13). As observed for other metals, sterically demanding SPOs such as $t$ - $\mathrm{Bu} \mathrm{P}_{2} \mathrm{P}(\mathrm{O}) \mathrm{H}$ were unable to coordinate the metal centre by either the oxygen or phosphorus atom. ficiently the alkyne, increasing the cationic character of the resulting vinyl-ruthenium intermediate and so favour nucleophilic attack. However, for electron-rich substrate $37(\mathrm{R}=\mathrm{OMe})$, the rate-determining step seems to be no longer the nucleophilic attack, in this case the reductive elimination process would be accelerated by the electron-rich ligands.

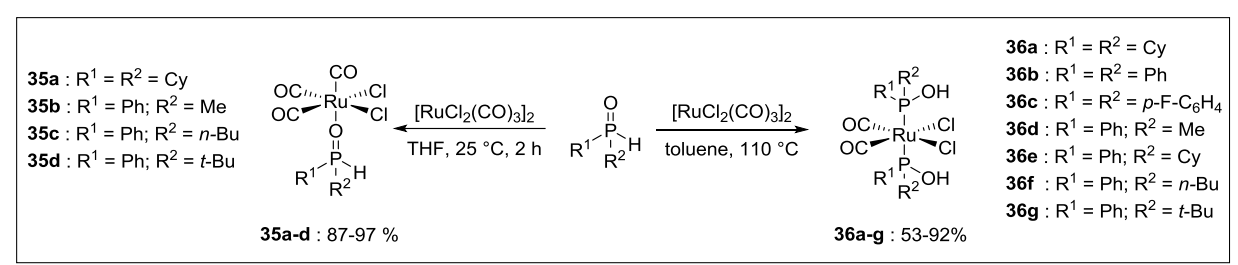

Scheme 13. Preparation of Ru-SPO complexes.

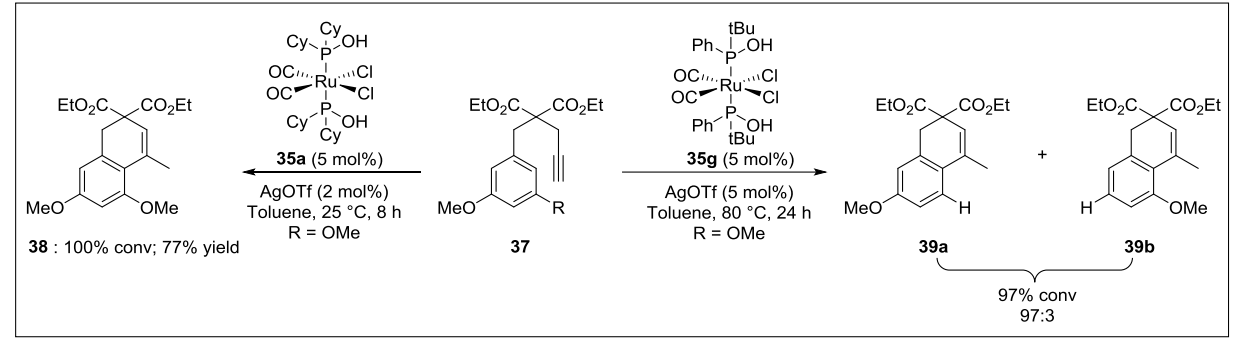

Scheme 14. Cycloisomerisation of arenynes. 


\section{Gold-Phosphinous Acid Complexes}

Coordination of SPO on gold is relatively unexplored, indeed only a few SPOgold complexes are described in the literature by Schmidbaur and co-workers. ${ }^{[62]}$ Mostly they describe the coordination chemistry of the diphenylphosphine oxide derivative giving complexes such as $\left[\mathrm{Ph}_{2} \mathrm{P}(\mathrm{OH}) \mathrm{AuCl}\right]_{2}$.

\section{Hydrogenation Using Gold Nanoparticles}

Until last year no SPO-gold complexes were used either in homogenous and heterogeneous catalysis. Stimulated by obtaining stable SPO-RuNPs, Van Leuween and co-workers used $[t$-Bu(naphthalen$1-\mathrm{yl}) \mathrm{P}(\mathrm{OH}) \mathrm{AuCl}]_{2}$ as a precursor to successfully stabilise gold nanoparticles. ${ }^{[63]}$ Their preparation requires two-step syntheses starting from [(tht)AuCl]; the final step produces, in presence of $\mathrm{NaBH}_{4}$, the desired SPO-Au nanoparticles. This procedure provides monodisperse particles $(1.24 \mathrm{~nm})$ which are highly soluble in apolar solvents. Thankfully their non-solubility in methanol allows a simple purification by precipitation. Structural and spectral analyses indicate that SPO $\mathbf{4 0}$ coordinates the gold surface in monodentate fashion as an anionic ligand instead of the classic $\mathrm{H}$ bonded 'bidentate' coordination.

The authors report a highly chemoselective hydrogenation of $\alpha, \beta$-unsaturated aldehydes 41 in which only the thermodynamically more robust $\mathrm{C}=\mathrm{O}$ group is reduced in alcohol to give products $\mathbf{4 2}$ (Scheme 15). The homogenous catalytic system displayed a high tolerance toward a wide range of functional groups such as alkynes, cyano, nitro, sulphur heteroaromatic rings, esters and carboxylic acids giving again a very high selectivity up to $99 \%$.[62] Of particular interest for this unprecedented selectivity is the hydrogenation of acrolein to allyl alcohol. Other AuNPs were evaluated to give no reactivity, highlighting the crucial role of the SPO in the reported catalytic activity.

\section{Cycloisomerisation of Enynes}

More recently, Fensterbank and coworkers described new SPO-gold(I) complexes and used them as catalysts in cycloisomerisation of enynes and hydroxyand methoxycyclisation reactions. ${ }^{[11]}$ The $\left[\mathrm{R}_{2} \mathrm{P}(\mathrm{OH}) \mathrm{AuCl}\right]$ complexes were generated simply by mixing dimethylsulfide gold(I) with the desired SPO which coordinates the metal centre through its phosphorus atom. The gold complex $\mathbf{4 3}$ displayed an interesting catalytic activity in the cycloisomerisation of several enynes $44(\mathrm{X}=$ $\left.\mathrm{C}\left(\mathrm{CO}_{2} \mathrm{Me}\right)_{2}\right)$ giving good yields using mild reaction conditions (Scheme 16). Interest-

$\mathrm{R}=\mathrm{H}$, Alkyl, Aryl,heterocyclic

Scheme 15. Hydrogenation of $\alpha, \beta$-unsaturated aldehydes. ingly this catalytic combination is able to promote the reaction even with deactivated substrates 44. Finally, the authors successfully applied the $[t-\mathrm{BuPhP}(\mathrm{OH}) \mathrm{AuCl}]$ catalyst to both the methoxy- and hydroxyl cyclisation giving high yields in each case.

\section{Rhodium-Phosphinous Acid Complexes}

The first application of Rh-SPO complexes was disclosed in the early 1980s when Matsumoto's group used them as catalysts for hydroformylation of linear olefins. ${ }^{64]}$ Since then, other homogenous catalytic reactions have been investigated giving interesting results. The following section will highlight the latest results of $\mathrm{Rh}-\mathrm{SPO}$ catalysed reactions.

\section{Hydroformylation}

Börner and co-workers reported the use of four aryl-substituted SPOs as pre-ligands in the rhodium-catalysed hydroformylation of olefins (cyclohexene, 1-octene). [65] Using only $26 \mathrm{ppm}$ of [Rh] with a $\mathrm{Rh} / \mathrm{L}$ ratio of $1: 4$, this catalytic combination produced the desired aldehyde in moderate to good yield. In all cases, SPO-Rh catalysts exhibit a better activity than the corresponding $\mathrm{PPh}_{3}$ complex. For 1-octene, good reactivity (up to $88 \%$ yield) was observed, but only moderate $n$-selectivity (53\%) was achieved indicating a high isomerisation rate. Curiously, electron-poor pre-ligands failed to increase the $n$-selectivity and for the most electron-deficient pre-ligands the reaction did not occur at all, leaving the 1-octene totally intact. Finally protic solvents such as methanol are crucial to observe a good level of $n$-selectivity as they maintain the integrity of the pseudo 'bidentate' coordination. ${ }^{[17]}$ In an extension of this work, the authors described the use of diaryl-phosphite pre-ligands, so-called HASPOs (het- eroatom-substituted phosphine oxides). ${ }^{[66]}$ These ligands did not improve the activity and the $n$-selectivity was found to be lower than with SPO-Rh. Furthermore, a side reaction involving free SPO and aldehyde products generated $\alpha$-hydroxyphosphonic acid diesters and so reduced the concentration of pre-ligand and the activity of the resulting catalyst.

\section{Hydrogenation}

Association of SPOs with a rhodium centre applied to hydrogenation reactions was first achieved by Feringa and de Vries. [67] This work followed their seminal report on the use of iridium SPOs complexes for asymmetric hydrogenation of imines. ${ }^{[68]}$ Although these catalysts could be discussed here, the SPO-iridium complexes will be discussed in their own section and more closely associated to the asymmetric catalysis part.

In 2010, Pugin and Pfaltz synthesized new SPO-type ligands derived from chiral ferrocenyl and menthyl, JoSPOphos and TerSPOphos, respectively (Fig. 7). ${ }^{[69]}$ These ligands, when associated with $\left[\mathrm{Rh}(\mathrm{nbd})_{2}\right] \mathrm{BF}_{4}$ under mild conditions, $(2 \mathrm{~h}$, $25^{\circ} \mathrm{C}, 1$ bar $\mathrm{H}_{2}$ ) showed high activities and enantioselectivities in the hydrogenation of alkenes (90-99\% ee). ${ }^{[69]}$ The reactions were quite fast with turnover frequencies (TOF) around 2000-20000 $\mathrm{h}^{-1}$. However, moderate asymmetric inductions were observed with this catalytic system on hydrogenated $\alpha$ - and $\alpha$-ketoesters $(89 \% e e)$. Of note, for such substrates the best enantioselectivity was obtained combining a ruthenium source and JoSPOphos $\left(\mathrm{R}^{1}=t-\mathrm{Bu}\right.$; $92 \%$ ee). Interestingly, the authors clearly showed that the absolute configuration at the phosphorus atom governs the direction of the asymmetric induction.

In 2012, Ding and co-workers reported the serendipitous discovery of the hydrolysis of phosphoramidite ligands such as

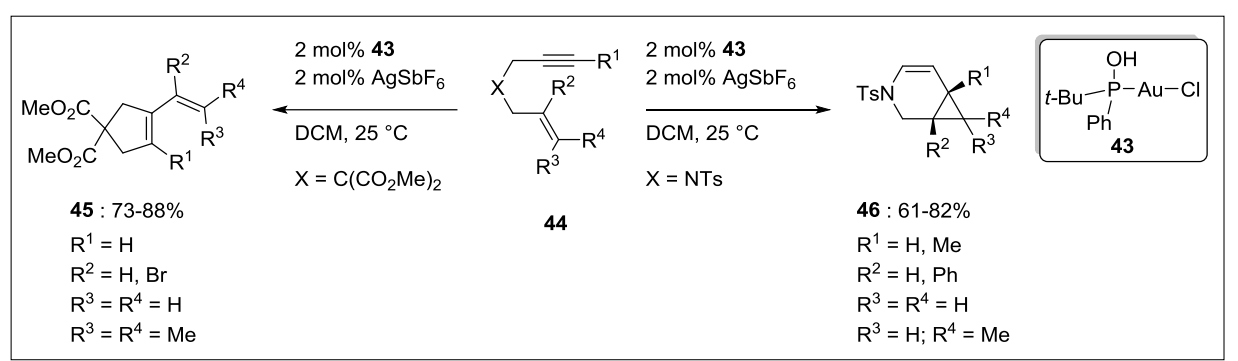

Scheme 16. Cycloisomerisation of enyne catalysed by SPO-Au complexes. 
DpenPhos into its corresponding secondary phosphine oxide form. ${ }^{\text {[70] }}$ This latest SPO-like $(S, S)-47$ pre-ligand and others were then applied successfully to the enantioselective rhodium-catalysed hydrogenation of $\alpha$-ethylphosphonic acids 48 . The authors reported both high reactivity $(0.01 \%<$ catalyst $)$ and enantioselectivity up to $98-99 \%$ for this SPO/Rh(I) combination (Scheme 17). ${ }^{[70]}$ This transformation occurs under relatively mild conditions at room temperature using only 10 bars of hydrogen producing product 49. X-ray characterisation of the pre-catalyst showed a pseudo 'bidentate' coordination of two SPO molecules arranged in a square planar fashion around the rhodium centre. The authors highlighted the fact that $\mathrm{H}$-bonding could be involved in the catalysis as poor conversions were observed in protic solvents. Finally this method was applied to the synthesis of fosmidomycin analogues (malaria parasite inhibitor). [70]

In an extension of simple and direct synthesis of valuable bioactive building blocks, the same authors described a SPO-rhodium(I) catalysed hydrogenation of challenging $\beta, \beta$-diarylacrylic acids ${ }^{[71]}$ 50 and $\alpha-\mathrm{CF}_{3} 52$ and $\beta-\mathrm{CF}_{3} 53$ substituted acrylic acids into corresponding $\beta, \beta$ diarylpropionic acids ${ }^{[72]} \mathbf{5 1}$ and trifluoromethylated propanoic acids $\mathbf{5 4}$ and $\mathbf{5 5}$ respectively (Scheme 18). In all cases they observed a synergistic effect ${ }^{[73]}$ combining achiral triphenyl phosphine and chiral SPO 56 resulting in a significant enhancement of both conversion (15\% to $99 \%$ ) and enantioselectivity (38\% to $95 \%$ ) compared with SPO used as the only ligand. This catalytic combination provides a straightforward methodology to diverse optically active substituted acid derivatives with biological importance.

More recently, Han and co-workers investigated other types of phosphorus ligands that are able to generate the pseudo 'bidentate' coordination mode. ${ }^{[74]} \mathrm{A}$ series of chiral phosphinate and phosphite were then explored in the asymmetric hydrogenation of $\alpha$-acetamidovinnamates. The easily accessible $\left(R_{p}\right)$-menthyl benzylphosphinate ligand 57 (Fig. 8) combined with cationic rhodium(I) salts produced the desired hydrogenated compound in high yield $(100 \%)$ and high enantiopurity (up to $99 \%$ ). Interestingly the chiral secondary phosphine oxide ligand $\left(\mathrm{R}^{1}=\mathrm{Ph} ; \mathrm{R}^{2}=t\right.$ $\mathrm{Bu}$ ) which produces the best asymmetric induction only gave $12 \% \mathrm{ee}$. These results show the potential and the complementarity of $\mathrm{H}$-phosphinate as an efficient chiral ligand for homogenous catalysis.

\section{Hydrogen Transfer}

The self-assembly of SPOs into anionic bidentate chelates, thanks to their ability to form strong intramolecular hydrogen

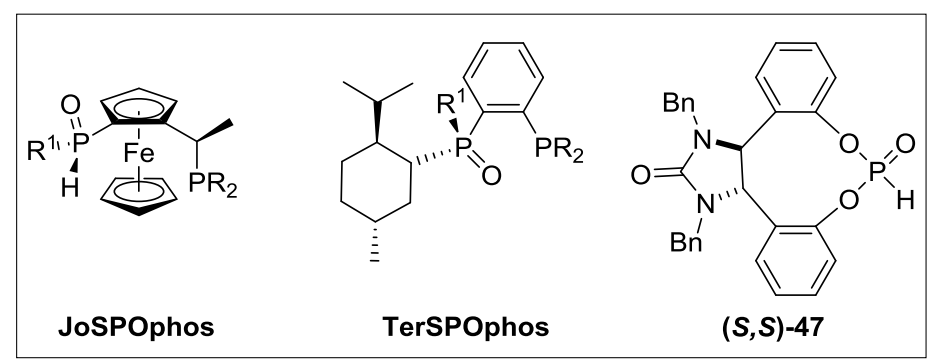

Fig. 7. Selected chiral SPO pre-ligands.

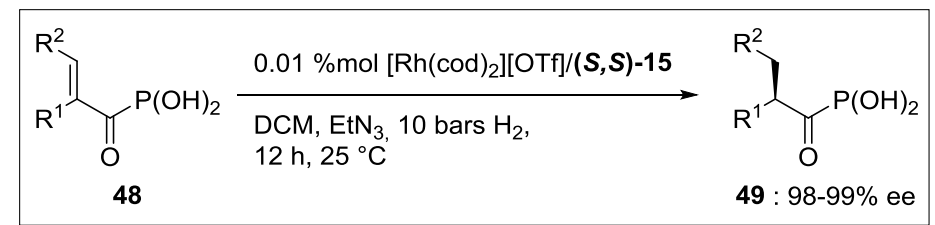

Scheme 17. Hydrogenation of $\alpha$-ethylphosphonic acids catalysed by SPO-Rh(I) complexes.

bonds between two SPO units, was developed by Castro et al. to construct unique systems for rhodium(III)-catalysed transfer hydrogenation of ketones. ${ }^{[75]}$ By simply mixing $\mathrm{RhCl}_{3}$ and the desired $\mathrm{SPO}$ in ethanol, the authors generated a neutral complex 58 (Fig. 9) that forms three intramolecular hydrogen bonds that do not interact with adjacent molecules. This re- activity; for example cyclohexanone needs a 1:10 ratio to achieve $92 \%$ conversion ( $R$ $\left.=\mathrm{Ph} ; \mathrm{TOF}=1825 \mathrm{~h}^{-1}\right)$. More fascinating is the result obtained using the BINOLderived chiral SPO 59 ligand (Fig. 9) that catalysed the asymmetric transfer hydrogenation of acetophenone with $89 \% e e$, employing isopropanol as the hydrogen donor. The positive linear effect observed

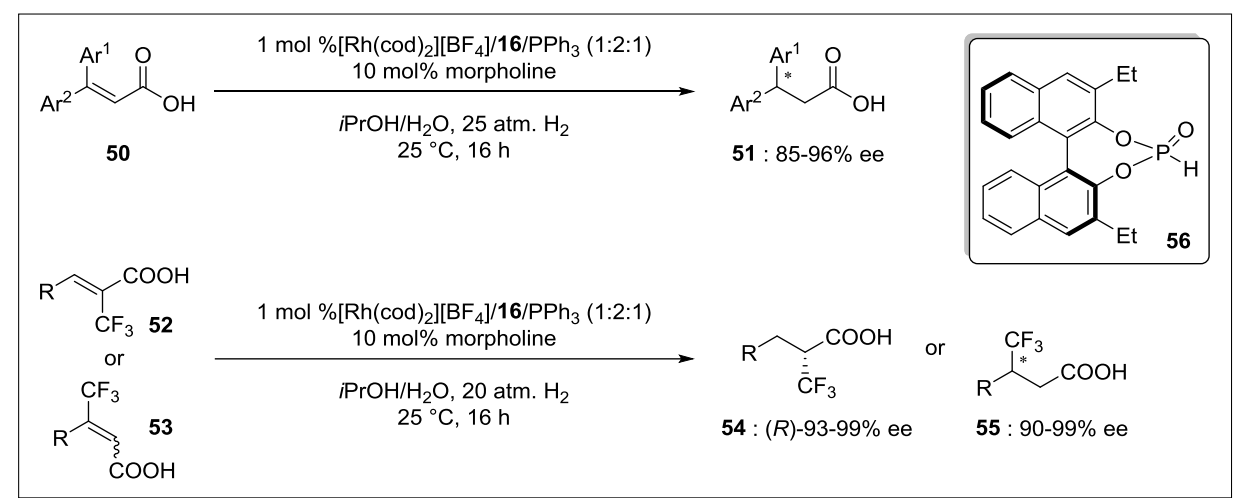

Scheme 18. Hydrogenation of $\alpha, \beta-\mathrm{CF}_{3}$ acrylic acids catalysed by SPO-Rh(I) complexes.

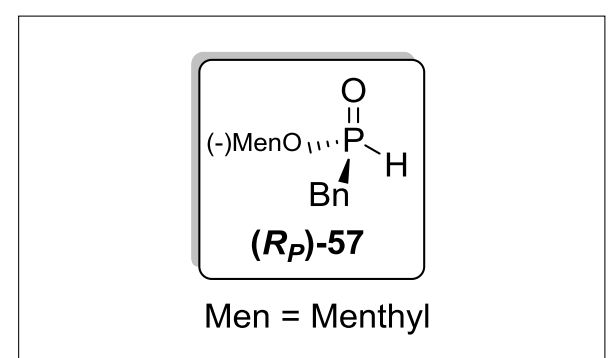

Fig. 8. Chiral 'SPO' derived from menthol.

sults in the adoption of both pseudo ' $b i$ dentate' or 'tridentate' coordination mode for the ensuing chelates. The best catalytic combination with a metal to ligand ratio of 1:10 for cyclohexanone (92\% conv.; TOF $\left.=1825 \mathrm{~h}^{-1}\right)$ and $1: 3$ for acetophenone $(18 \%$ conv.; TOF $=353 \mathrm{~h}^{-1}$ ) was established using $0.5 \mathrm{mM}$ of rhodium.

The metal to $\mathrm{R}_{2} \mathrm{P}(\mathrm{H}) \mathrm{O}$ ligand ratio was found to be crucial to obtain good catalytic by the authors confirmed the preference of a pseudo 'bidentate' chelating mode of the SPOs.

\section{Hydrolysis of Ammonia- and Amine-boranes}

Due to its high hydrogen capacity (19.6 wt\%) ammonia borane $\left(\mathrm{AB}, \mathrm{NH}_{3}-\mathrm{BH}_{3}\right)$ is considered an attractive candidate for chemical hydrogen storage applications. The dehydrocoupling of such a substrate catalysed by transition metals ${ }^{[76]}$ recently became a field of intensive investigation to efficiently produce hydrogen. ${ }^{[77]}$ One of the limitations of this method is that transition metal catalysts often require an inert atmosphere. Currently the most effective catalysts for this transformation are rhodium nanoparticles that allow the reaction to proceed at $25^{\circ} \mathrm{C}$ in air. ${ }^{[78]}$ Interestingly, only few metal catalysts are reported to be effective under homogenous conditions. 
Garralda et al. showed that ligands such as $o$-(diphenylphosphino)benzaldehyde can stabilise the hydridoirida- $\beta$-diketones complex 60 by strong O---H---O intramolecular hydrogen bonds. ${ }^{[79]}$

In this context, they prepared a rhodium(III) complex $\mathbf{6 0}$ bound by both a phosphine-acyl and a SPO ligand. The phosphinous acid provides the hydrogen atom to form the expected pseudo 'bidentate' coordination mode by intramolecular hydrogen bonding. These rhodium complexes were evaluated as catalysts for the hydrolytic release of hydrogen from ammonia- $(\mathrm{AB})$ or tertbutylamine- (TBAB) and dimethylamine-borane (DMAB) substrates. ${ }^{[80]}$ The reaction occurs under mild conditions: $40{ }^{\circ} \mathrm{C}$ in $\mathrm{THF} / \mathrm{H} 2 \mathrm{O}$ using only $0.5 \mathrm{~mol} \%$ of catalyst generating more than 2.5 equiv. of hydrogen (Scheme 19). Neutral complex 60 displayed better activities than the cationic complex and can be reused at least six times reproducing the kinetic profile. The recycling of the catalyst is easily achieved by simply reusing the leftover solution of a completed reaction as the solvent for the next.

\section{N-Coupling of Benzotriazoles}

In 2014, Breit and co-workers reported the rhodium-catalysed $N^{1}$-selective coupling of benzotriazoles with allenes. ${ }^{[81]}$ Due to the equilibrium between the $N^{1}$ and $N^{2}$ tautomers for 1,2,3-triazoles and especially for benzotriazole, a mixture of $N^{1}$ and $N^{2}$-subsituted benzotriazole products is often obtained. An exceptionally high $N^{1}$ selectivity (product 62) was achieved by using a catalytic combination of rhodium(I)/JoSPOphos (Scheme 20). The catalytic system was tolerant toward modifications on the benzotriazole backbone and to several allene substrates bearing protected hydroxyl and phthalimide groups for example. In addition, this SPO pre-ligand displayed a promising asymmetric induction of $46 \%$ ee for the corresponding cyclohexylallene adduct.

\section{Asymmetric N-Coupling of Pyrazoles}

Very recently, the same author described a SPO-rhodium-catalysed asymmetric $N$-selective coupling of pyrazole
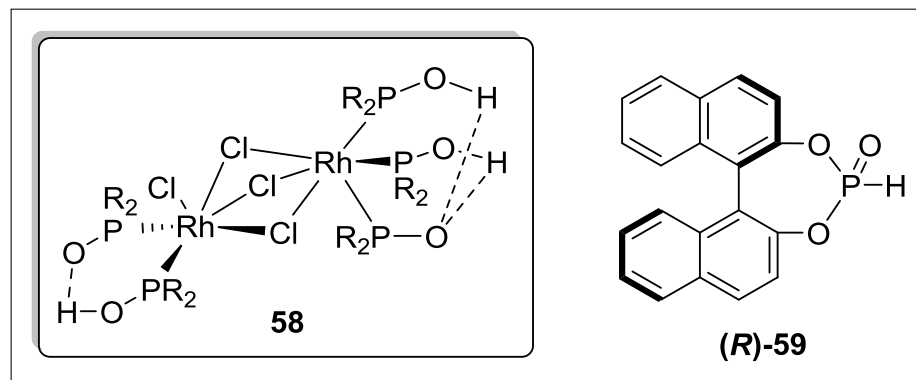

Fig. 9. Chiral 'SPO' derived from binaphthol.

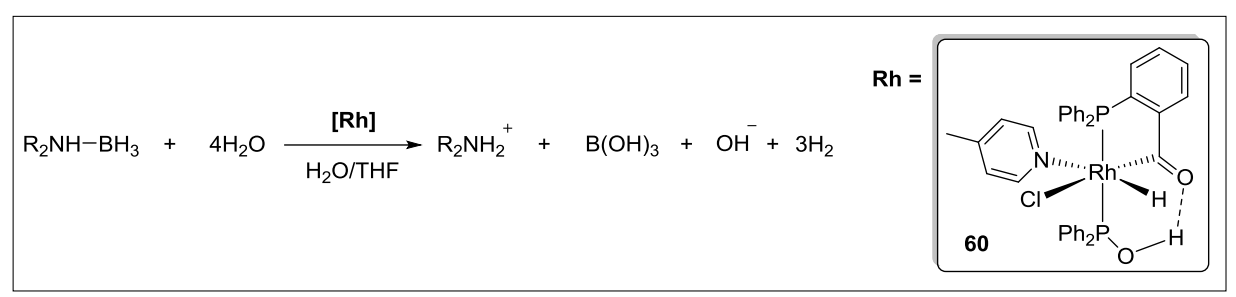

Scheme 19. Hydrolysis of amine-boranes catalysed by SPO-Rh(III) complexes. derivatives 63 with terminal allenes that give access to enantioenriched secondary 64 and tertiary 65 allylic pyrazoles. ${ }^{[82]}$

JoSPOphos was found to efficiently catalyse this asymmetric transformation giving both high regio- and enantioselectivity. The authors show that the presence of pyridinium $p$-toluenesulfonate (PPTS) is crucial to achieve high regioselectivity providing the $N^{1}$ product (Scheme 21). A wide range of substituted 4-pyrazoles 64 were tested giving the corresponding allylic pyrazoles in good to excellent yields and enantioselectivities (Scheme 21). ${ }^{[82]}$ Halogen, alkyl, fluoroalkyl, phenyl groups at the 4-position and unsubstituted pyrazoles were well tolerated. However, for electronwithdrawing groups a slight decrease in the reactivity was observed without a negative impact on the ee values (up to $91 \%$ ). The allene partner was then evaluated; once again the $N^{l}$ product was obtained in good yield and high enantiopurity starting either from mono- and 1,1-disubstituted allenes. The system was also flexible with various functional groups such as phthalimide, thioether, ether, silyl-ether and alcohol.

Substitution at the C(3)- or C(5)-position concomitant to the $\mathrm{C}(4)$ position appears to slightly decrease the regioselectivity in some cases but enantioselectivity remains high in all cases (Scheme 22). ${ }^{[82]}$ Globally, electron-rich pyrazoles led to the desired $N 1$ products 67 in excellent yields with high enantiomeric excess, but with a slightly lower regioselectivity compared to electron-poor ring systems that provide both high regio- and enantioselectivities.

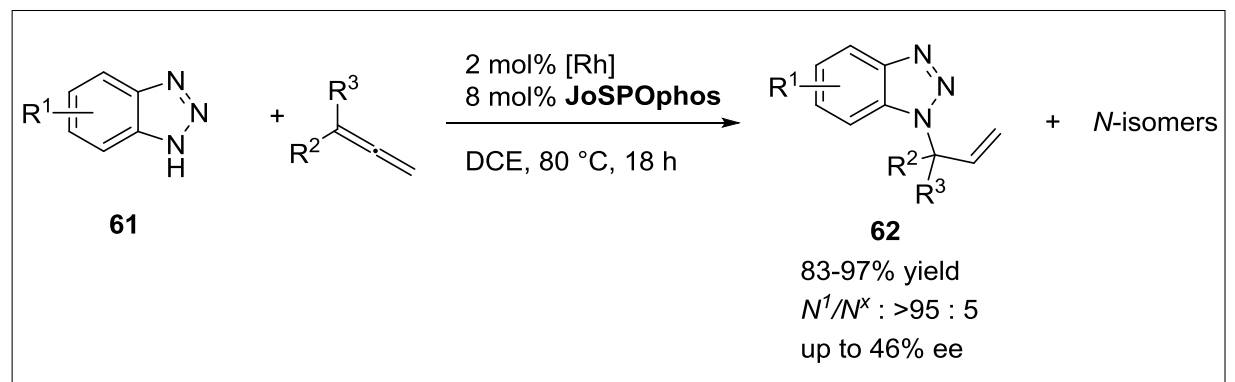

Scheme 20. $N$-coupling of benzotriazoles catalysed by SPO-Rh(I) complexes.

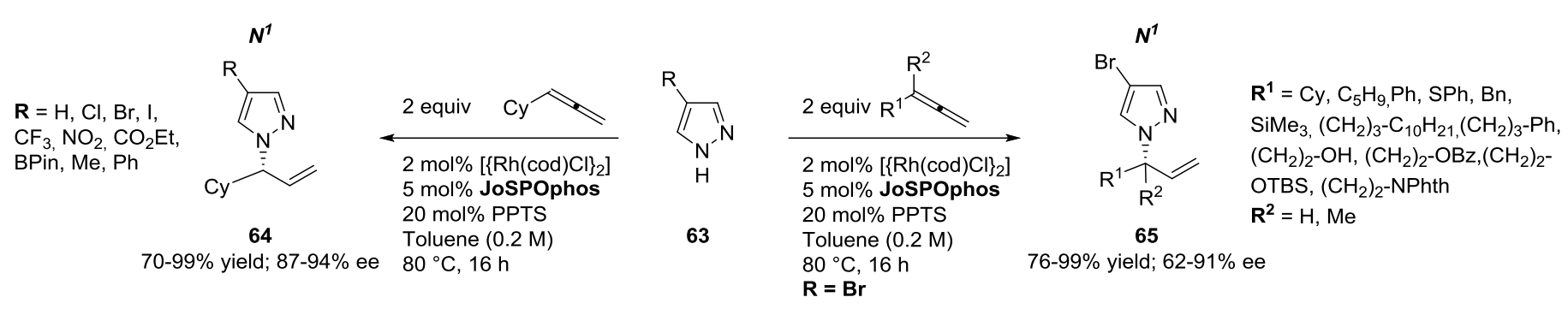




\section{Bimetallic Catalysis}

As mentioned in the introduction, SPOs ligands are able to coordinate two different metal centres through both its phosphorus and oxygen atoms. Generally, SPOs react with soft metal ions giving the phosphinous acid complex, which in the presence of a base, react with other metal species (often hard ions) either generating type (h) metallacycle or type (e) bridged complexes (see Scheme 2).[6a,7a,83] Several bifunctional metal complexes have been prepared with different combinations such as Pd-Ti, ${ }^{[16]} \mathrm{Pt}-\mathrm{Ir}$ and $\mathrm{Pt}-\mathrm{Rh},{ }^{[84]} \mathrm{Fe}-\mathrm{Rh},{ }^{[85]}$ and others. Curiously the use of such heterobimetallic complexes that would have some cooperative effect in catalysis is largely uninvestigated in this area. ${ }^{[86]}$ Only the nickel/magnesium bimetallic combination has been suggested with secondary phosphine oxides for Kumada-Corriu cross-couplings of aryl fluorides. ${ }^{[87]}$

Very recently, the group of Cramer developed an asymmetric hydrocarbonylation of homoallylic formamides 69 catalysed by a hetero-bimetallic SPOs nickel/ alumina enantiopure complex. ${ }^{[88]}$ First of all, the phosphinous acid form reacts with $\mathrm{Al}(\mathrm{Me})_{3}$ through its hydroxyl group, releasing a molecule of methane and provides an O-coordinated complex type (d). For the formation of catalytically active aluminium-phosphinous acid-Ni complex,

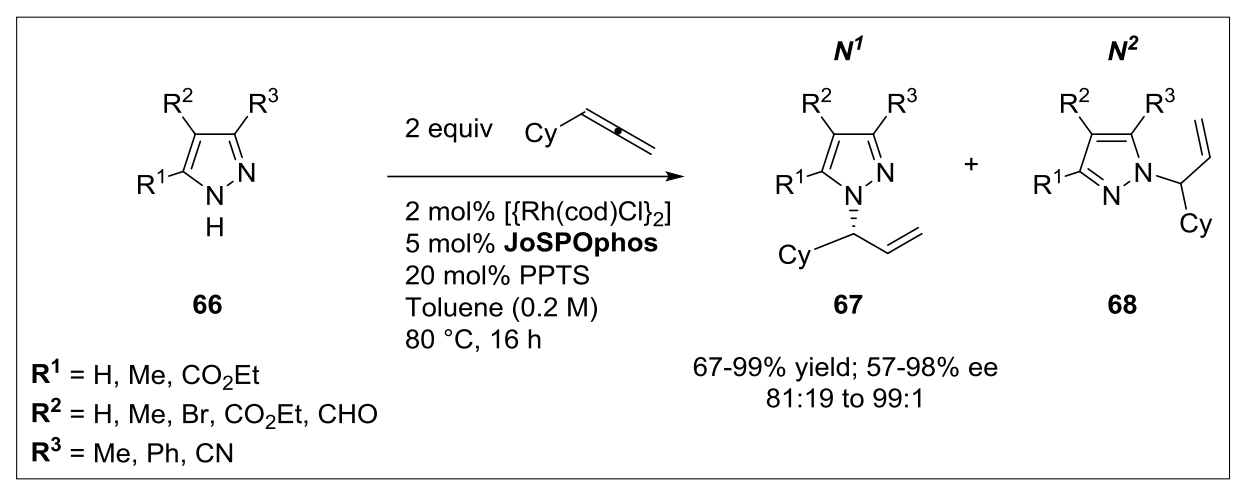

Scheme 22. Enantioselective addition of symmetric 3,4- or 3,5-substituted pyrazoles to substituted terminal allenes.

$0.5 \mathrm{~mol} \%$ without affecting the selectivity of the reaction $(96.5: 3.5)$. Several formamide substrates 69 and 74 were then examined, varying both the substituent on the nitrogen atom and the number of allylic chains (see Scheme 24). ${ }^{[88]}$ The observed selectivity is not related to the substituent on the nitrogen atom as different groups such as alkyl, aryl, benzyl or ester generate similar levels of selectivity. Bis-allylated formamides $\mathbf{7 4}$ lead to the desired lactam adducts $\mathbf{7 5}$ in high yield and enantioselectivities. Interestingly the good diastereoselectivity obtained in this case, point to a good enantiocontrol in the selection of one of the two enantiotopic allyl groups.

Finally, the authors show that this catalytic system could dictate its own enantio- control over a stereogenic centre present in the substrate 76 (Scheme 25). ${ }^{[88]}$ Indeed the matched case produces a high diastereoselectivity $(16: 1)$ and the mismatched one a moderate but inverse $d r(3: 1)$. The chelation of both metals is suggested to facilitate the $\mathrm{C}-\mathrm{H}$ activation process by placing the low-valent nickel metal centre in close proximity to the formamide. The tight geometry of the intermediate might be responsible for the good enantiodiscrimination in the hydrometalation step.

\section{Asymmetric Catalysis}

The desymmetrisation of the SPOs (different $\mathrm{R}$ groups) makes the phospho-

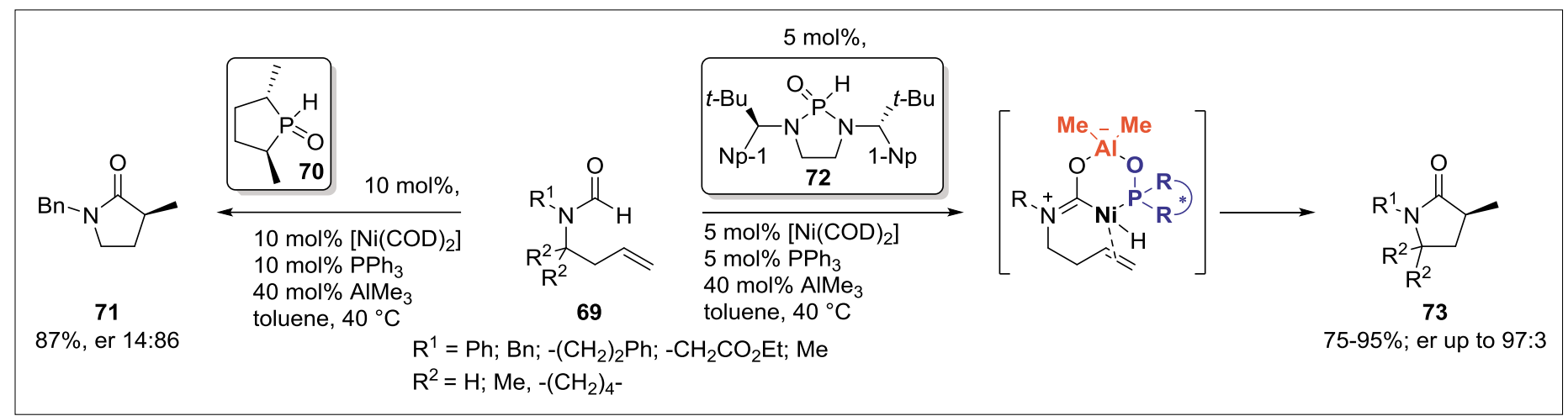

Scheme 23. Enantioselective hydrocarbamoylation catalysed by SPO-Ni/Al complexes.

the use of $\mathrm{PPh}_{3}$ was found essential to displace the cycloctadiene from the nickel to allow the coordination of the SPO preligand. Enantioenriched SPO 70 derived from phospholane, under mild conditions (toluene, $40{ }^{\circ} \mathrm{C}, 12 \mathrm{~h}$ ), provides $\gamma$-lactam 71 in good yield and interesting enantiomeric ratio (er: 14:86, Scheme 23).

Inspired by the seminal work of Hama$\mathrm{da}^{[89]}$ in the use of chiral diaminophosphine oxides (DIAPHOXs) in catalytic transformation, the authors developed a new chiral HASPO catalyst $\mathbf{7 2}$ from the ethylene diamine backbone. ${ }^{[88]}$ Using this SPO DIAPHOXs ligand 72, the authors were able to reduce the catalyst loading from 10 to

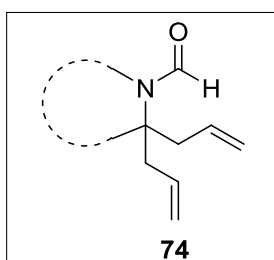

$5 \mathrm{~mol} \% 72$

$5 \mathrm{~mol} \%$ [Ni(COD)2]

$5 \mathrm{~mol} \% \mathrm{PPh} 3$

$40 \mathrm{~mol} \% \mathrm{AlMe}_{3}$

toluene, $40^{\circ} \mathrm{C}$

74

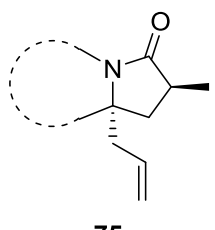

75

$77-98 \%$; er up to $97.5: 2.5$

Scheme 24

Enantioselective

hydrocarbamoylation catalysed by SPO-

$\mathrm{Ni} / \mathrm{Al}$ complexes.

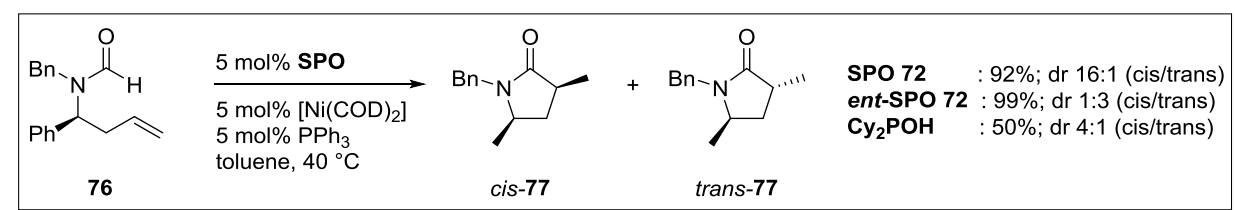

Scheme 25. Matched/mismatched stereocontrol of chiral SPO 72. 
rus atom stereogenic, providing a doorway to asymmetric catalysis. Fortunately, the stereochemistry at the phosphorus atom is retained throughout the equilibrium between the secondary phosphine oxide and the phosphinous acid. These chiral SPO ligands ${ }^{[90]}$ are accessible via several methods such as optical resolution, ${ }^{[91]}$ chiral chromatography, ${ }^{[68]}$ nucleophilic substitution on chiral (-)-menthyl phenylphosphinate, ${ }^{[22 \mathrm{~b}, \mathrm{c}]}$ and dynamic resolution $^{[92]}$ for example. ${ }^{[24,93]}$ These characteristics indeed make them very attractive ligands in asymmetric catalysis. Since the first report by Minnaard, Feringa and de Vries on asymmetric hydrogenation catalysed by the P-chiral SPOs (40, 78)/iridium system, ${ }^{[68]}$ other asymmetric transformations have been successfully explored. ${ }^{[24 a, 94]}$ Enantiopure SPOs were successfully used in rhodium-catalysed alkene hydrogenation (SPO-40, 58, 59, 81, JoSPOphos, TerSPOphos; Scheme 17 and Scheme 18, Fig. 10),[67,69,74] SPO-80/palladium-catalysed allylic substitution, ${ }^{[89 a, 95]}$ SPO-25/palladium-catalysed allylic amination ${ }^{[89 b, 96]}$ and SPO-78/palladium-catalysed [2+1] cycloaddition. ${ }^{[97]}$ Finally, RhJoSPOphos complexes displayed a high regio- and enantioselectivity for $N 1$-substitution for both benzotriazoles and pyrazoles substrates. ${ }^{[81,82]}$

\section{Conclusion}

Due notably to their air and moisture stability, secondary phosphine oxides (SPOs) represent a new and attractive alternative to classic phosphine ligands. These pre-ligands have been successfully employed in several metal-catalysed reactions. Clearly the results indicated that SPOs are more than just 'phosphine mimics' possessing their own special characteristics and promoting original reactivity. The easy modularity of both steric and electronic properties of these ligands makes them attractive for catalysts and new reactivity screening. More precisely, the electronic properties of SPOs shows an extraordinary range, going from $\pi$-accepting phosphite-like compounds, to extremely electron-donating ligands outclassing $N$-heterocyclic carbenes. ${ }^{[18]}$ Once coordinated to the metal centre through the phosphorus atom, the resulting $\mathrm{OH}$ group may act as an acid, as a directing group and as a pendant base responsible for the interesting activity of SPO-metal complexes. These ligand-metal cooperative effects were found crucial to stabilize ruthenium and gold-nanoparticles providing highly active catalysts. The ability to form pseudo 'bidentate' anionic ligands is not limited solely to SPOs. Phosphinate and phosphite, often synthetic intermediates,

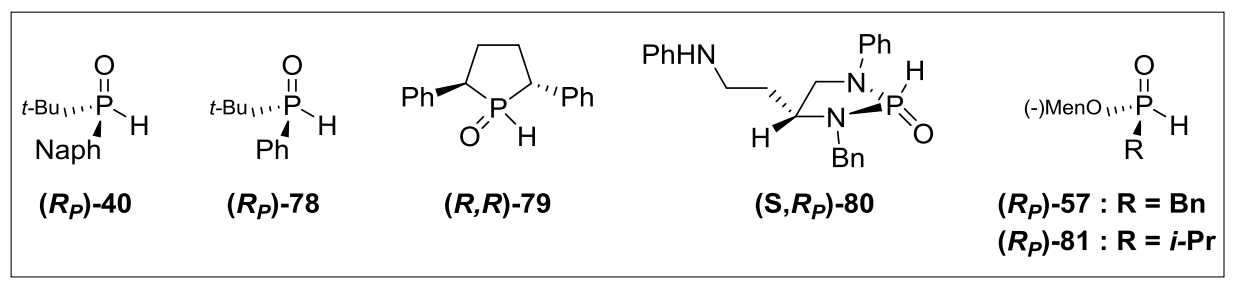

Fig. 10. Chiral SPOs, DIAPHOXs and HASPOs ligands.

displayed as well this talent and showed promising reactivities. ${ }^{[74]}$ Complementary to this, heteroatom-substituted phosphine oxides (HASPO) and diaminophosphine oxides (DIAPHOXs) were also found to be very interesting ligands displaying high activity. ${ }^{[98]}$ Due to their original catalytic activity, all these pre-ligands should be used to reinvestigate classic metal-catalysed reactions. Finally, the use of simple combinations of various groups (alkyl, aryl, alkoxy or aryloxy) bound to the phosphorus atom would bring more diversity and quickly generate a large library of ligands. Promising but still limited results were obtained in asymmetric catalysis using chiral phosphine oxides. However synthesis of enantioenriched SPOs is currently a growing field of investigation.

\section{Acknowledgements}

I would like to thank particularly Prof. Gérard Buono, Dr. Alphonse Tenaglia, Dr. Hervé Clavier, and Dr. Laurent Giordano (IsM2-Chirosciences, UMR 7313, Marseille) who gave me the opportunity to discover such a fascinating field.

Received: March 31, 2015

[1] 'A Guide to Organophosphorus Chemistry', Ed. L. D. Quin, John Wiley \& Sons, New York, 2000.

[2] 'Phosphorus Ligands in Asymmetric Catalysis - Synthesis and Application', Ed. A. Börner, Wiley-VCH: Weinheim, 2008.

[3] a) W. J. Tang, X. M. Zhang, Chem. Rev. 2003, 103, 3029; b) K. V. L. Crepy, T. Imamoto, New Aspects in Phosphorus Chemistry Iii 2003, 229, 1.

[4] M. Ohff, J. Holz, M. Quirmbach, A. Borner, Synthesis 1998, 1391.

[5] a) J. Chatt, B. T. Heaton, J. Chem. Soc. A 1968 , 2745; b) A. Christiansen, C. Li, M. Garland, D. Selent, R. Ludwig, A. Spannenberg, W. Baumann, R. Franke, A. Boerner, Eur. J. Org. Chem. 2010, 2733.

[6] a) D. M. Roundhill, R. P. Sperline, W. B. Beaulieu, Coord. Chem. Rev. 1978, 26, 263; b) G. Manca, M. Caporali, A. Ienco, M. Peruzzini, C. Mealli, J. Organomet. Chem. 2014, 760, 177.

[7] a) B. Walther, Coord. Chem. Rev. 1984, 60, 67; b) T. Appleby, J. D. Woollins, Coord. Chem. Rev. 2002, 235, 121.

[8] D. Magiera, A. Szmigielska, K. M. Pietrusiewicz, H. Duddeck, Chirality 2004, 16, 57.

[9] J.-N. Li, L. Liu, Y. Fu, Q.-X. Guo, Tetrahedron 2006, 62, 4453 .

[10] The crystallographic data for complexes have been obtained free of charge via the Cambridge Crystallographic Data Centre and cif files were reprocessed using Ortep software.
[11] F. Schroeder, C. Tugny, E. Salanouve, H. Clavier, L. Giordano, D. Moraleda, Y. Gimbert, V. Mouries-Mansuy, J.-P. Goddard, L. Fensterbank, Organometallics 2014, 33, 4051.

[12] L. V. Graux, M. Giorgi, G. Buono, H. Clavier, Organometallics 2015, 34, 1864.

[13] N. W. Alcock, P. Bergamini, T. M. GomesCarniero, R. D. Jackson, J. Nicholls, A. G. Orpen, P. G. Pringle, S. Sostero, O. Traverso, J. Chem. Soc., Chem. Commun. 1990, 980.

[14] A. M. Z. Slawin, M. Wainwright, J. Derek Woollins, New J. Chem. 2000, 24, 69.

[15] T. Achard, L. Giordano, A. Tenaglia, Y. Gimbert, G. Buono, Organometallics 2010, 29, 3936.

[16] T. Mizuta, C. Miyaji, T. Katayama, J.-i. Ushio, K. Kubo, K. Miyoshi, Organometallics 2009, 28,539 .

[17] A. Christiansen, D. Selent, A. Spannenberg, W. Baumann, R. Franke, A. Boerner, Organometallics 2010, 29, 3139.

[18] D. Martin, D. Moraleda, T. Achard, L. Giordano, G. Buono, Chem. Eur. J. 2011, 17, 12729.

[19] a) J. Bigeault, L. Giordano, I. De Riggi, Y. Gimbert, G. Buono, Org. Lett. 2007, 9, 3567; b) L. Ackermann, H. K. Potukuchi, A. R. Kapdi, C. Schulzke, Chem. Eur. J. 2010, 16, 3300.

[20] a) P. van Leeuwen, C. F. Roobeek, R. L. Wife, J. H. G. Frijns, J. Chem. Soc. Chem. Com. 1986, 31; b) P. van Leeuwen, C. F. Roobeek, J. H. G. Frijns, A. G. Orpen, Organometallics 1990, 9 , 1211.

[21] L. Ackermann, Synthesis 2006, 1557.

[22] a) T. L. Emmick, R. L. Letsinger, J. Am. Chem. Soc. 1968, 90, 3459; b) A. Leyris, J. Bigeault, D. Nuel, L. Giordano, G. Buono, Tetrahedron Lett. 2007, 48, 5247; c) Q. Xu, C.-Q. Zhao, L.B. Han, J. Am. Chem. Soc. 2008, 130, 12648; d) A. J. Bloomfield, J. M. Qian, S. B. Herzon, Organometallics 2010, 29, 4193.

[23] a) N. V. Dubrovina, A. Borner, Angew. Chem. Int. Ed. 2004, 43, 5883; b) L. Ackermann, Synlett 2007, 507

[24] a) T. M. Shaikh, C.-M. Weng, F.-E. Hong, Coord. Chem. Rev. 2012, 256, 771; b) T. Nemoto, Y. Hamada, Tetrahedron 2011, 67, 667.

[25] a) G. Y. Li, G. Zheng, A. F. Noonan, J. Org. Chem. 2001, 66, 8677; b) G. Y. Li, Angew. Chem. 2001, 113, 1561; c) G. Y. Li, P. J. Fagan,

[26] C. Wolf, R. Lerebours, J. Org. Chem. 2003, 68, 7077.

[27] C. Wolf, R. Lerebours, J. Org. Chem. 2003, 68, 7551.

[28] C. Wolf, R. Lerebours, Org. Biomol. Chem. 2004, 2, 2161.

[29] a) C. Wolf, R. Lerebours, E. H. Tanzini, Synthesis 2003, 2069; b) C. Wolf, R. Lerebours, Org. Lett. 2004, 6, 1147.

[30] C. Wolf, H. Xu, J. Org. Chem. 2008, 73, 162.

[31] H. Xu, K. Ekoue-Kovi, C. Wolf, J. Org. Chem. 2008, 73, 7638.

[32] a) W. Yang, Y. Wang, J. R. Corte, Org. Lett. 2003, 5, 3131; b) R. R. Poondra, P. M. Fischer, N. J. Turner, J. Org. Chem. 2004, 69, 6920; c) S. P. Khanapure, D. S. Garvey, Tetrahedron Lett. 2004, 45, 5283; d) P. Cao, J. Qu, G. Burton, R. A. Rivero, J. Org. Chem. 2008, 73, 7204; e) K. L. Billingsley, S. L. Buchwald, Angew. Chem. Int. Ed. 2008, 47, 4695; f) D. X. Yang, S. L. 
Colletti, K. Wu, M. Song, G. Y. Li, H. C. Shen, Org. Lett. 2009, 11, 381; g) Y.-Y. Chang, F.-E. Hong, Tetrahedron 2013, 69, 2327.

[33] K. Ekoue-Kovi, H. Xu, C. Wolf, Tetrahedron Lett. 2008, 49, 5773.

[34] R. Lerebours, A. Camacho-Soto, C. Wolf, J. Org. Chem. 2005, 70, 8601.

[35] Z. Zhang, Z. Hu, Z. Yu, P. Lei, H. Chi, Y. Wang, R. He, Tetrahedron Lett. 2007, 48, 2415.

[36] R. Lerebours, C. Wolf, Org. Lett. 2007, 9, 2737.

[37] L. Ackermann, R. Vicente, N. Hofmann, Org. Lett. 2009, 11, 4274.

[38] R. Lerebours, C. Wolf, J. Am. Chem. Soc. 2006, 128, 13052.

[39] a) S. Wang, Z. Zhang, Z. Hu, Y. Wang, P. Lei, H. Chi, J. Environ. Sci.-China 2009, 21 Suppl 1, S124; b) Z. Zhang, Z. Hu, S. Wang, P. Lei, H. Chi, R. He, J. Environ. Sci.-China 2009, 21 Suppl 1, S65; c) B. Li, C. Wang, G. Chen, Z. Zhang, J. Environ. Sci-China 2013, 25, 1083.

[40] D.-F. Hu, C.-M. Weng, F.-E. Hong, Organometallics 2011, 30, 1139.

[41] T. M. Shaikh, F. E. Hong, Beilstein J. Org. Chem. 2013, 9, 1578.

[42] Y.-C. Chang, W.-C. Chang, C.-Y. Hu, F.-E. Hong, Organometallics 2014, 33, 3523.

[43] J. Bigeault, L. Giordano, G. Buono, Angew. Chem. Int. Ed. 2005, 44, 4753.

[44] J. Bigeault, I. de Riggi, Y. Gimbert, L. Giordano, G. Buono, Synlett 2008, 1071.

[45] a) T. Ghaffar, A. W. Parkins, Tetrahedron Lett. 1995, 36, 8657; b) T. Ghaffar, A. W. Parkins, $J$. Mol. Catal. A: Chem. 2000, 160, 249.

[46] a) T. J. Ahmed, S. M. M. Knapp, D. R. Tyler, Coord. Chem. Rev. 2011, 255, 949; b) R. Garcia-Alvarez, P. Crochet, V. Cadierno, Green Chem. 2013, 15, 46.

[47] W. F. Yates, R. L. Heider, J. Am. Chem. Soc. 1952, 74, 4153.

[48] S. M. M. Knapp, T. J. Sherbow, J. J. Juliette, D. R. Tyler, Organometallics 2012, 31, 2941.

[49] a) T. J. Ahmed, B. R. Fox, S. M. M. Knapp, R. B. Yelle, J. J. Juliette, D. R. Tyler, Inorg. Chem. 2009, 48, 7828; b) S. Knapp, T. Sherbow, T. Ahmed, I. Thiel, L. Zakharov, J. J. Juliette, D. Tyler, J. Inorg. Organomet. Polym. Mater. 2014, $24,145$.

[50] T. Achard, A. Lepronier, Y. Gimbert, H. Clavier, L. Giordano, A. Tenaglia, G. Buono, Angew. Chem. Int. Ed. 2011, 50, 3552.

[51] L. Ackermann, Org. Lett. 2005, 7, 3123.

[52] a) L. Ackermann, A. Althammer, R. Born, Angew. Chem. Int. Ed. 2006, 45, 2619; b) L. Ackermann, Isr. J. Chem. 2010, 50, 652; c) L. Ackermann, A. V. Lygin, Org. Lett. 2011, 13, 3332; d) L. Ackermann, M. Mulzer, Org. Lett. 2008, 10, 5043.

[53] For reviews see: a) L. Ackermann, Acc. Chem. Res. 2014, 47, 281; b) L. Ackermann, Org. Process Res. Dev. 2015, 19, 260.

[54] L. Ackermann, E. Diers, A. Manvar, Org. Lett. 2012, 14, 1154.

[55] R. Garcia-Alvarez, J. Francos, E. TomasMendivil, P. Crochet, V. Cadierno, J. Organomet. Chem. 2014, 771, 93.

[56] S. M. M. Knapp, T. J. Sherbow, R. B. Yelle, J. J. Juliette, D. R. Tyler, Organometallics 2013, 32, 3744 .
[57] E. Tomas-Mendivil, F. J. Suarez, J. Diez, V. Cadierno, Chem. Commun. 2014, 50, 9661.

[58] E. Tomas-Mendivil, L. Menendez-Rodriguez, J. Francos, P. Crochet, V. Cadierno, RSC Adv. 2014, 4, 63466.

[59] F. Wang, W. E. Buhro, J. Am. Chem. Soc. 2012, $134,5369$.

[60] E. Rafter, T. Gutmann, F. Loew, G. Buntkowsky, K. Philippot, B. Chaudret, P. W. N. M. van Leeuwen, Catal. Sci. Technol. 2013, 3, 595.

[61] a) R. Torres-Lubián, M. J. Rosales-Hoz, A M. Arif, R. D. Ernst, M. A. Paz-Sandoval, J. Organomet. Chem. 1999, 585, 68; b) C. J. den Reijer, M. Wörle, P. S. Pregosin, Organometallics 2000, 19, 309.

[62] a) H. Schmidbaur, A. A. M. Aly, Angew. Chem. Int. Ed. 1980, 19, 71; b) C. Hollatz, A. Schier, H. Schmidbaur, J. Am. Chem. Soc. 1997, 119, 8115 ; c) C. Hollatz, A. Schier, J. Riede, H. Schmidbaur, J. Chem. Soc., Dalton Trans. 1999 111; d) C. Hollatz, A. Schier, H. Schmidbaur, Inorg. Chim. Acta 2000, 300, 191.

[63] I. Cano, A. M. Chapman, A. Urakawa, P. W. N. M. van Leeuwen, J. Am. Chem. Soc. 2014, 136, 2520.

[64] M. Matsumoto, M. Tamura, J. Mol. Catal. 1983, 19,365 .

[65] A. Christiansen, C. Li, M. Garland, D. Selent, R. Ludwig, R. Franke, A. Boerner, Chemcatchem 2010, 2, 1278.

[66] A. Christiansen, D. Selent, A. Spannenberg, M. Koeckerling, H. Reinke, W. Baumann, H. Jiao, R. Franke, A. Boerner, Chem. Eur. J 2011, 17, 2120.

[67] X. B. Jiang, M. van den Berg, A. J. Minnaard, B. L. Feringa, J. G. de Vries, TetrahedronAsymmetry 2004, 15, 2223.

[68] X. B. Jiang, A. J. Minnaard, B. Hessen, B. L. Feringa, A. L. L. Duchateau, J. G. O. Andrien, J. A. F. Boogers, J. G. de Vries, Org. Lett. 2003 , $5,1503$.

[69] H. Landert, F. Spindler, A. Wyss, H.-U. Blaser, B. Pugin, Y. Ribourduoille, B. Gschwend, B. Ramalingam, A. Pfaltz, Angew. Chem. Int. Ed. 2010, 49, 6873 .

[70] K. Dong, Z. Wang, K. Ding, J. Am. Chem. Soc. 2012, 134, 12474.

[71] Y. Li, K. Dong, Z. Wang, K. Ding, Angew. Chem. Int. Ed. 2013, 52, 6748.

[72] K. Dong, Y. Li, Z. Wang, K. Ding, Angew. Chem. Int. Ed. 2013, 52, 14191.

[73] Y. T. Fan, M. Cong, L. Peng, Chem. Eur. J 2014, 20, 2698.

[74] X.-B. Wang, M. Goto, L.-B. Han, Chem. Eur. J 2014, 20, 3631.

[75] P. M. Castro, H. Gulyas, J. Benet-Buchholz, C. Bo, Z. Freixa, P. W. N. M. van Leeuwen, Catal. Sci. Technol. 2011, 1, 401.

[76] A. Staubitz, A. P. M. Robertson, I. Manners, Chem. Rev. 2010, 110, 4079.

[77] a) H. W. Langmi, G. S. McGrady, Coord. Chem. Rev. 2007, 251, 925; b) T. Umegaki, J.-M. Yan, X.-B. Zhang, H. Shioyama, N. Kuriyama, Q. $\mathrm{Xu}$, Int. J. Hydrogen Energ. 2009, 34, 2303.

[78] M. Fetz, R. Gerber, O. Blacque, C. M. Frech, Chem. Eur. J. 2011, 17, 4732.

[79] M. A. Garralda, R. Hernández, L. Ibarlucea, E. Pinilla, M. R. Torres, Organometallics 2003, 22, 3600 .
[80] V. San Nacianceno, L. Ibarlucea, C. Mendicute-Fierro, A. Rodriguez-Dieguez, J. M. Seco, I. Zumeta, C. Ubide, M. A. Garralda, Organometallics 2014, 33, 6044.

[81] K. Xu, N. Thieme, B. Breit, Angew. Chem. Int. Ed. 2014, 53, 7268.

[82] A. M. Haydl, K. Xu, B. Breit, Angew. Chem. Int. Ed. 2015, 54, 7149.

[83] T. Appleby, J. D. Woollins, Coord. Chem. Rev. 2002, 235, 121.

[84] L. R. Falvello, J. Forniés, A. Martín, J. Gómez, E. Lalinde, M. T. Moreno, J. Sacristán, Inorg. Chem. 1999, 38, 3116.

[85] H. Brunner, R. Eder, B. Hammer, U. Klement, J. Organomet. Chem. 1990, 394, 555.

[86] a) R. M. Bullock, C. P. Casey, Acc. Chem. Res. 1987, 20, 167; b) N. Wheatley, P. Kalck, Chem. Rev. 1999, 99, 3379; c) B. G. Cooper, J. W. Napoline, C. M. Thomas, Catal. Rev. 2012, 54, 1.

[87] a) L. Ackermann, A. Althammer, Chemie in unserer Zeit 2009, 43, 74; b) Z. Jin, Y.-J. Li, Y.-Q. Ma, L.-L. Qiu, J.-X. Fang, Chem. Eur. J. 2012, $18,446$.

[88] P. A. Donets, N. Cramer, J. Am. Chem. Soc. 2013, 135, 11772.

[89] a) T. Nemoto, T. Matsumoto, T. Masuda, T. Hitomi, K. Hatano, Y. Hamada, J. Am. Chem. Soc. 2004, 126, 3690; b) T. Nemoto, T. Masuda, Y. Akimoto, T. Fukuyama, Y. Hamada, Org. Lett. 2005, 7, 4447.

[90] L. Ackermann, 'Chiral Secondary Phosphine Oxides and Heteroatom-Substituted Secondary Phosphine Oxides as Preligands' in 'Phosphorus Ligands in Asymmetric Catalysis', Vol. I-III, Ed.: A. Boerner, Wiley-VCH, Weinheim, 2008, pp. 831-847.

[91] a) J. Drabowicz, P. Lyzwa, J. Omelanczuk, K. M. Pietrusiewicz, M. Mikolajczyk, TetrahedronAsymmetry 1999, 10, 2757; b) R. K. Haynes, T. L. Au-Yeung, W. K. Chan, W. L. Lam, Z. Y. Li, L. L. Yeung, A. S. C. Chan, P. Li, M. Koen, C. R. Mitchell, S. C. Vonwiller, Eur. J. Org. Chem. 2000, 3205; c) A. Leyris, D. Nuel, L. Giordano, M. Achard, G. Buono, Tetrahedron Lett. 2005, 46, 8677; d) J. Holt, A. M. Maj, E. P. Schudde, K. M. Pietrusiewicz, L. Sieron, W. Wieczorek, T. Jerphagnon, I. W. C. E. Arends, U. Hanefeld, A. J. Minnaard, Synthesis 2009, 2061; e) M. Stankevic, K. M. Pietrusiewicz, J. Org. Chem. 2007, 72, 816 .

[92] F. A. Kortmann, M.-C. Chang, E. Otten, E. P. A. Couzijn, M. Lutz, A. J. Minnaard, Chem. Sci. 2014, 5, 1322.

[93] O. I. Kolodiazhnyi, Tetrahedron: Asymmetry 2012, 23, 1.

[94] For a recent review see: ref. [24a].

[95] a) W.-M. Dai, K. K. Y. Yeung, W. H. Leung, R. K. Haynes, Tetrahedron: Asymmetry 2003, 14, 2821; b) T. Nemoto, T. Sakamoto, T. Fukuyama, Y. Hamada, Tetrahedron Lett. 2007, 48, 4977.

[96] T. Nemoto, T. Fukuyama, E. Yamamoto, S. Tamura, T. Fukuda, T. Matsumoto, Y. Akimoto, Y. Hamada, Org. Lett. 2007, 9, 927.

[97] D. Gatineau, D. Moraleda, J.-V. Naubron, T. Buergi, L. Giordano, G. Buono, TetrahedronAsymmetry 2009, 20, 1912.

[98] L. Ackermann, Isr. J. Chem. 2010, 50, 652. 